\title{
Oxidative/nitrative stress in the pathogenesis of systemic sclerosis: are antioxidants beneficial?
}

\section{Paul Ames, Tommaso Bucci, Mira Merashli, Marta Amaral, Alessia Arcaro, Fabrizio Gentile, Jaffar Nourooz-Zadeh \& Jose DelgadoAlves}

To cite this article: Paul Ames, Tommaso Bucci, Mira Merashli, Marta Amaral, Alessia Arcaro, Fabrizio Gentile, Jaffar Nourooz-Zadeh \& Jose DelgadoAlves (2018): Oxidative/nitrative stress in the pathogenesis of systemic sclerosis: are antioxidants beneficial?, Free Radical Research, DOI: 10.1080/10715762.2018.1525712

To link to this article: https://doi.org/10.1080/10715762.2018.1525712

Accepted author version posted online: 18 Sep 2018.

Submit your article to this journal $₫$

View Crossmark data $\nearrow$ 


\title{
Oxidative/nitrative Stress in the Pathogenesis of Systemic Sclerosis: are Antioxidants Beneficial?
}

\author{
Paul RJ Ames ${ }^{1,2}$, Tommaso Bucci ${ }^{3}$, Mira \\ Merashli $^{4}$, Marta Amaral ${ }^{1}$, Alessia Arcaro ${ }^{5}$
}

Fabrizio Gentile ${ }^{5}$, Jaffar Nourooz-Zadeh ${ }^{6}$, Jose’ Delgado-Alves ${ }^{1,7}$

1,Immune Response and Vascular Disease Unit, CEDOC, Nova University, Rua Câmara Pestana 6, 1150-082, Lisbon, Portugal; Phone: (+351) 218803 038 (ext 22492) \& 2Department of Haematology, Dumfries Royal Infirmary, Cargenbridge, DG2 8RX, Dumfries, UK, paxmes@aol.com; 3Department of Internal Medicine, Division of Allergy and Clinical Immunology, University of Salerno, Via S. Allende - 84081 - Baronissi (SA), Italy, tombuc@hotmail.it; ${ }^{4}$ Department of Rheumatology, American University of Beirut, Bliss,Beirut, Lebanon, phone: (+961) 1-350000,dr.merashli@hotmail.com; 5Department of Medicine \& Health Sciences, Universita' del Molise, Via Francesco De Sanctis, 1, 86100 Campobasso, Italy, phone (+39) 0874 4041,alessia.arcaro@unimol.it, gentilefabrizio@unimol.it; ${ }^{6}$ Nephrology and Urology Research Centre, Urmia University of Medical Sciences, West Azarbayjan,Urmia, Iran; (+98) 443223 4897, jaffarnouroozzadeh@yahoo.co.uk; 1,7Immunomediated Systemic Diseases Unit, Medicine4, Hospital Fernando Fonseca, C19, 2720-276 Amadora,Portugal; marta.amaral@nms.unl.pt, jose.alves@nms.unl.pt.

Corresponding author: ${ }^{1}$ Immune Response and Vascular Disease Unit, CEDOC, Nova University, Rua Câmara Pestana 6, 1150-082, Lisbon, Portugal; Phone: (+351) 218803 038 (ext 22492), paxmes@aol.com; 


\begin{abstract}
Systemic sclerosis ( $\mathrm{SSc}$ ) is a multisystem autoimmune disease: characterised from the clinical side by progressive vasculopathy and fibrosis of the skin and different organs and from the biochemical side by fibroblast deregulation with excessive production of collagen and increased expression of nicotinamide adenine dinucleotide phosphate oxidase 4 (NOX4). The latter contributes to an overproduction of reactive oxygen species that via an autocrine loop maintains NOX4 in a state of activation. Reactive oxygen and nitrogen species are implicated in the origin and perpetuation of several clinical manifestations of SSc having vascular damage in common; attempts to dampen oxidative and nitrative stress via different agents with antioxidant properties have not translated into sustained clinical benefit. Objective of this narrative review is to describe the origin and clinical implications of oxidative and nitrative stress in SSc, with particular focus on the central role of NOX4 and its interactions, to re-evaluate the antioxidant approaches so far employed to limit disease progression, to appraise the complexity of antioxidant treatment and to touch on novel pathways elements of which may represent specific treatment targets in the not so distant future.
\end{abstract}

Key words: systemic sclerosis, NOX, Nfr2, oxidative stress, antioxidant

\title{
List of abbreviations
}

LA: alpha-lipoic acid

ABI: ankle brachial index

Ang II: angiotensin II 
ARE: antioxidant responsive elements

ADMA: asymmetric dimethyl arginine:

CFR: coronary flow reserve

CAT: catalase

DAMP: damage associated molecular pattern:

DcSSc: diffuse cutaneous systemic sclerosis:

DHLA: Dihydrolipoic acid

PEN: penicillamine

Endothelial cells: EC

eNOS:endothelial nitric oxide synthase

ET-1: endothelin-1

FAD: flavin adenine dinucleotide

FPP: farnesyl-pyrophosphate

FMD: flow mediated dilation

GGPP: geranyl-geranyl-pyrophosphate

GSH: Glutathione:

HR: Hazard ratio

HMG-CoA: reductase Hydroxy-3-methylglutaryl-coenzyme A reductase

HNN: hydroxynonenal

HO-1: haemo- oxygenase-1

iNOS: inducible nitric oxide synthase

IL: interleukin

LcSSc: Limited cutaneous systemic sclerosis

L-NAME: N-Nitroarginine methyl ester

MDA: Malondialdehyde

NAC: N-acetylcysteine

NOX: nicotinamide adenine dinucleotide phosphate oxidase

NMD: nitroglycerine mediated dilatation

NPC: nitrosoperoxocarbonate

NT: nitrotyrosine

Nrf2: nuclear erythroid-derived factor-2

NFkB:nuclear factor kappa B

OR: odds ratio

PDGF: platelet-derived growth factor

PDGFR:platelet-derived growth factor receptor:

PI3K: phosphoinositide-3 kinase

PKC: protein kinase $\mathrm{C}$

RNS: reactive nitrogen species 
ROS: reactive oxygen species

RP: Raynaud's phenomenon

SOD: superoxide dismutase

SSc: systemic sclerosis

BH4: tetrahydrobiopterin:

TLR: Toll-like receptor

TGF- $\beta$ :transforming growth factor beta

VEGF:vascular endothelial growth factor

\section{Introduction}

Systemic sclerosis $(\mathrm{SSc})$ is a chronic autoimmune disorder characterized by a progressive non inflammatory vasculopathy with intimal hyperplasia affecting small and large arteries [1] and by excessive production of collagen, fibronectin and other matrix proteins which accumulate in the skin and internal organs, resulting in fibrosis[2]. Free radical production is enhanced in SSc in relation to some clinical manifestations as indicated in the following paragraphs. [3] While the review focuses on the interplay between reactive oxygen species (ROS) generated by NOX and TGFbeta, inflammasome and Nrf2 in the pathogenesis of fibrosis, we must touch on how the immune system is affected by ROS in SSc.

\section{Notes on Oxidative/Nitrative Stress and Immunity in Systemic Sclerosis}

Oxidative stress is a measure of the prevailing levels of reactive oxygen species (ROS) in biological systems determined by the relative rates of their formation and their removal by plasma and cellular repair mechanisms [3]. In given micro-environments excess ROS produced by neutrophils, endothelial cells and monocytes contributes to free radical 
attack on membrane and/or lipoprotein lipids in a process called lipid peroxidation[4].

Nitric oxide (NO•) generated from arginine by the action of nitric oxide synthases (NOS) regulates several biological processes including vasomotor tone. Upon reaction with superoxide anion $\left(\mathrm{O}^{2 \bullet-}\right), \mathrm{NO} \bullet$ forms peroxynitrite (ONOO-), which interacts with $\mathrm{CO}^{2}$ to form nitrosoperoxocarbonate $\left(\mathrm{ONOOCO}^{2-}\right)$. Aromatic amino acyl (tryptophanyl, tyrosyl, phenylalanyl), cysteinyl and methionyl residues of proteins are sensitive to modification by different forms of reactive nitrogen species (RNS), depending upon the availability of $\mathrm{CO}^{2}$ and $\mathrm{pH}$ [3]. ONOO- is not only responsible for the nitration of tyrosyl residues in proteins [5] but also for the formation of nitro-fatty acids that may modulate metabolic- and anti-inflammatory pathways [6,7]

Oxidative stress may lead to cell/tissue damage by several mechanisms: by the oxidative modification of cell macromolecules (DNA, proteins, lipids) that may occur by direct metal-catalyzed oxidation of amino acyl side chains and by the formation of covalent adducts of the products of carbohydrate oxidation, advanced glycoxidation end products (AGE), with DNA and proteins of crucial importance for cell viability. Auto-fluorescence of SSc skin reveals the presence of AGE in relation to carotid radial pulse wave velocity and capillary flow percentage change during occlusion[8].

Moreover, the peroxidation of polyunsaturated fatty acids in phosphatidylcholine and other phospholipids in cell membranes and in low density lipoprotein yield 1) $\gamma$ hydroxy-alkenals generically called ALE that include acrolein, malonyldialdehyde and 2) an $\alpha, \beta$-unsaturated hydroxyalkenal called and 4-hydroxy-2-nonenal (4-HNE) that may form adducts with cysteine,lysine and histidine residues inducing post-translational modifications in those proteins bearing such residues (5) and 2)a family of cyclic molecules called isoprostanes, generated independently of cyclooxygenase, that are sensitive and specific markers of oxidative stress and that have powerful vasoactive properties [3].

The engagement of oxidation-specific epitopes (OSE), including AGE/ALEs and relevant adducts with DNA and proteins to scavenger receptors including RAGE induce the activation of NF-\#B [10] in endothelial cells, macrophages and dendritic cells thereby promoting inflammatory and immune responses. The relevance of RAGE 
stimulation in SSc is highlighted by the report concerning the secretion of alarmins (S100A8 and S100A9) from monocytes and neutrophils that bind to TLR4 and RAGE, thereby recruiting and activating leukocytes into inflamed tissues[9].

The oxidative modification of self-epitopes with the consequent sensitization to mixed self/non-self neoepitopes and the breaking of immunological tolerance to their native counterparts, leads to immuno-mediated cell and tissue damage and the appearance of autoantibodies. Various pro-oxidative agents (bleomicin, superoxide anions, hydroxyl radicals, hypochlorous acid and peroxynitrite) injected in immune deficient mice induced the development of serum anti-centromeric protein-B and antiDNA topoisomerase 1 autoantibodies. On the other hand, sera of oxidatively treated mice (hypochlorite or hydroxyl radical) and of patients with diffuse SSc contained high levels of ALE that triggered endothelial production of $\mathrm{H}^{2} \mathrm{O}^{2}$ and fibroblast hyperproliferation[9].

\section{Nicotinamide Adenine Dinucleotide Phosphate Oxidase in Systemic Sclerosis}

The main source of ROS in the organism is the NOX family, composed of five different NOX isoforms. NOX enzymes are characterized by six transmembrane domains and two cytosolic domains respectively for NADPH and for flavin adenine dinucleotide[10]. NOX reduces molecular oxygen, forming superoxide anion $\mathrm{O}^{2} \bullet$ - and hydrogen peroxide (H202), using NADPH as an electron donor that is transferred first to the FAD and then to a heme group. Of the different NOX isoforms, NOX4 is particularly relevant to SSc: 1) though present on the surface of fibroblasts, vascular smooth muscles cells (VSMC) and endothelial cells (EC)[11]NOX4 is constitutively expressed on dermal fibroblast [12] as it lacks cytosolic regulatory subunits, and therefore depends almost exclusively on the amount of p22phox expressed on the cellular membrane[13]; 2) NOX4 does not generate $\mathrm{O}^{2} \bullet$ - but almost exclusively $\mathrm{H}_{2} \mathrm{O} 2$; the latter does not react with $\mathrm{NO} \bullet$ to yield ONOO-[14]. Other cell types produce enhanced of ROS in SSc such as circulating neutrophils, monocytes [15] and T lymphocytes [16]. 


\section{Nicotinamide Adenine Dinucleotide Phosphate Oxidase and Toll Like Receptors}

Toll-like receptors (TLR) are a family of pattern recognition receptors (PRR) that sense invading pathogens or endogenous damage signals and once stimulated initiate the innate and adaptive immune response. Damage associated molecular patterns (DAMP) appearing during the course of oxidation and nitration including post-translational modification of certain connective tissue proteins and heat shock proteins also stimulate TLR[17,18]. The intracellular signalling triggered by TLR activation is mediated by the cytoplasmic adaptor molecule, MyD88 and by the serine/threonine kinases of the IL-1R-associated kinase family, resulting in translocation of NF- KB to the nucleus and synthesis of type I interferons and inflammatory cytokines[19]. TLR4 is a better sensor for oxidative stress than other TLRs[20]. Interestingly, TLR4 and its co-receptors, MD2 and CD14, are over-expressed in affected skin from patients with diffuse cutaneous SSc; the same study demonstrated in a mouse model that chronic TLR4 stimulation is associated with increased expression of the TGF- $\beta$ gene[21]. Others have also demonstrated overexpression of TLR9 (an endosomal TLR) in the skin of SSc patients of SSc mice in parallel with overexpression of TGF- $\beta$ [22]. Conversely in vitro studies show that TGF- $\beta$ stimulated the expression of NOX4 both in normal dermal and in SSc dermal fibroblasts via the $\mathrm{PKC}-\delta$ and the $\operatorname{Smad} 2 / 3$ pathways[23] and that TGF$\beta$ increases the expression of NOX4 in normal human lung fibroblasts[24].

\section{Nicotinamide Adenine Dinucleotide Phosphate Oxidase and Inflammasomes}

The inflammasome is a multiprotein oligomer that promotes the maturation and secretion of pro-inflammatory cytokines involved in the inflammatory response; the phagocyte inflammasome NLRP3 requires a two step signal for its activation: a priming transcriptional step that involves NF-אB pre-activation by TLR2, TLR3, TLR4, and TLR7 and a post-translational step that allows the oligomerization of the inflammasome components followed by the maturation and secretion of IL-1 $\beta[25]$. ROS participates indirectly through the activation of TRL involved in the priming step and directly at the 
post-translational step[26]. ROS of NOX origin are critical for NLRP3 inflammasome activation though mitochondrial ROS are also relevant[27].

The inflammasome is involved in the pathogenesis of SSc: a clinical study reported over-expression of NLRP3 in affected skin of SSc patients compared to healthy individuals: NLRP3, caspase-1, IL-1 $\beta$, IL-18 and (endothelin-1) ET-1 were overexpressed in affected skin of limited and diffuse SSc whereas limited SSc patients showed a significant increase in eNOS, iNOS and TGF- $\beta$. The expression of NLRP3, IL-1 $\beta$, IL-18 and ET-1 correlated with dermal fibrosis in limited SSc[28]. In vitro studies on SSc fibroblasts show that inflammasome activation favoured the expression of 40 genes involved in the synthesis of signalling. Moreover inhibition of caspase-1 in dermal and lung SSc fibroblasts abrogated the secretion of collagens, IL-1 $\beta$, and IL-18[29]. A definitive proof for inflammasome involvement in fibrosis comes from the mouse model of bleomycin-induced skin fibrosis where NLRP (- - ) mice failed to develop fibrosis after bleomicin exposure[30]

\section{Nicotinamide Adenine Dinucleotide Phosphate Oxidase \& Antioxidant Responsive}

\section{Elements}

The activity of NOX4 is also closely related to that of nuclear erythroid-derived factor-2 (Nrf2), the most important nuclear transcriptional factor involved in the expression of genes coding for the synthesis of antioxidant enzymes[31]. In fact, Nrf2, interacting with the Maf protein, binds the antioxidant responsive elements (AREs) in proximity of the promoters of the genes coding for glutathione (GSH) biosynthesis and regeneration (glutamate-cysteine ligase), for the thioredoxin system (eg thioredoxin reductase), for the detoxification of ROS (eg NADPH quinone oxidoreductase-1) and for heme and iron metabolism (eg heme oxygenase-1)[32]. This cross-talk is fundamental to restore the oxidative-redox balance upset by excessive NOX4 generated ROS: the protective role of NOX4 on the cardiovascular system[33] is due to the ability to promote growth, proliferation and migration of endothelial cells[34]. In this scenario, NOX4 producing $\mathrm{H} 2 \mathrm{O} 2$ induces $\mathrm{p} 38 \mathrm{MAPK}$; this in turn activates eNOS with consequent production of 
$\mathrm{NO} \bullet$ that restores endothelial and vascular function[35]. Moreover, thanks to its ability to react with cysteine residues forming disulfide bridges, $\mathrm{H} 2 \mathrm{O} 2$ is an important mediator for many transcription factors and enzymes involved in the regulation of oxidative stress[14].

\section{Nicotinamide Adenine Dinucleotide Phosphate Oxidase and Fibrogenesis}

Several fibrogenic cytokines such as TGF- $\beta$, platelet-derived growth factor (PDGF) and angiotensin II (Ang II) induce the expression of NOX4 in various cell lines enhancing thus the production of ROS.

The TGF- $\beta$ induced NOX4 expression through the Smad 2/3 and the phosphoinositide3kinase (PI3K) pathways[36] is particularly relevant at the pulmonary level: hypoxia stimulates the release of TGF $\beta$ from epithelial cells that, fibrosis aside, stimulates threefold the expression of NOX4 on EC and VSMC favoring thus the transformation of VSMC into myofibroblasts[37]; this causes a severe structural remodeling the intima of the pulmonary vessels[38] that leads to pulmonary hypertension, one of the lethal complications of SSc.

Platelet, macrophage and fibroblast derived PDGF[39] synergizes with TGF- $\beta$ : in fact PDGF increases the production and mediates some of the effects of TGF- $\beta$, whereas TGF- $\beta$ stimulates PGDF in a positive feedback loop[40]. The intimal hyperplasia characteristic of the early stages of SSc is associated with an over expression of PDGF receptor (PDGFR) in EC and VSMC[41] that behaves as an autoantigen against which activating autoantibodies can be formed[42]. Upon activation, PDGFRs trigger a Ras, ERK1/2 and PI3K dependent intracellular pathway that stimulates NOX4 to produce $\mathrm{H} 2 \mathrm{O} 2$ which in turn activates fibroblasts resulting in further extracellular matrix deposition[12,43].

AngII is a peptide that regulates vasomotor tone: its precursor angiotensinogen is produced by the liver and is subsequently transformed into AngII through cleavage first by the renin and subsequently by the angiotensin converting enzyme. Increased expression of Ang II is detected within the skin lesions of SSc[44]. By binding to its type 
1 receptor Ang II activates NOX4 which produces $\mathrm{H}^{2} \mathrm{O}^{2}$ and induces the decoupling of the eNOS, stimulates the production of TGF- $\beta$ and activates PKC which by means of ERK1/2 induces the deposition of proteins of the extracellular matrix with consequent fibrosis[45].

\section{Oxidative and Nitrative Stress markers in Systemic Sclerosis}

A recent meta-analysis including 47 articles and 12 oxidative stress markers confirmed an oxidant/antioxidant imbalance in SSc:oxidative markers such as NO•, asymmetric dimethyl arginine (ADMA), malondialdehyde (MDA), carbonyls and ROOH were higher in SSc than in control groups whereas the antioxidant vitamins $\mathrm{E}$ and $\mathrm{C}$, and thiols were lower alongside a decreased enzymatic activity of superoxide dismutase (SOD) and catalase (CAT)[46]. Another meta-analysis confirmed overproduction of isoprostanes in $\mathrm{SSc}[47]$.

More recently an imbalance of the vanin/pantetheinase system emerged as a contributor to oxidative stress in $\mathrm{SSc}$; the hydrolysis of vasculoprotective pantethine generates pantothenic acid that has profibrotic effects and cysteamine (then cystamine) that has pro-oxidant effects[48]. In turn cystamine directly[49] and indirectly via the $\mathrm{Nfr} 2$ pathway[50] inhibits directly $\gamma$-glutamyl synthetase, the rate-limiting enzyme of glutathione (GSH) synthesis that has strong free radical scavenging effects. Diffuse cutaneous (dcSSc) patients overexpress vanin-1 in the skin and the circulatory system, and display elevated levels of serum pantothenic acid in relation to disease severity [51].

\section{Micro/macrovascular Disease in Systemic Sclerosis: Functional Studies}

The initial functional and structural hallmarks of microvasculature changes in SSc are Raynaud's phenomenon (RP) and the morphological abnormalities seen at capillaroscopy [52]. Endothelial dysfunctionmay be present at this early stage, whereby the loss of NO• bioavailability determines an impairment of endothelium-dependent 
arterial vasodilation alongside a pro-inflammatory and pro-thrombotic state[53]. A systematic review and meta-analysis on 7 studies and 283 SSc patients dealing with functional vascular measurements revealed impaired flow mediated dilation (FMD) with wide heterogeneity[54] though one study did not favour the impairment. A later meta-analysis including 35 studies and 1292 patients came to similar conclusions though 4 studies did not favour the association. On the other hand nitroglycerine mediated vasodilatation was not affected[55]. Microvascular involvement underlies subclinical cardiac disease: a study on 19 asymptomatic SSc patients revealed decreased coronary flow reserve $(\mathrm{CFR})$ compared to controls $(\mathrm{p}<0.001)$; CRF was lower in dcSSc than in the limited cutaneous SSc patients $(\mathrm{lcSSc})(\mathrm{p}=0.05)$; interestingly CRF was inversely correlated with the time of onset of RP[56]. Functional microvascular impairment may be simultaneously present with functional macrovascular impairment[57] but the recent meta-analysis onfive studies concluded that ankle brachial index did not discriminate SSc from healthy controls [55].

\section{Micro/macrovascular Disease in Systemic Sclerosis: Morphological Studies}

According to different methodologies the prevalence of macrovascular involvement can be as high as 58\% [58]. A systematic review and meta-analysis on atherosclerosis measured as intima media thickness of carotid arteries on 14 studies including $666 \mathrm{SSc}$ patients revealed greater intima media thickness with wide heterogeneity [54]. The same systematic review concluded that sub-clinical atherosclerosis was present in specific districts such as the renal, radial and ulnar arteries [54] with the latter two leading to ischaemia, ulceration or amputation of fingers [59-61].

A population based study calculated the hazard ratio (HR) for developing acute myocardial infarction at 3.49, the HR being higher at 8.95 within the first year of SSc diagnosis [62] whereas a later study identified SSc as an independent risk factor for acute myocardial infarction (HR 2.45) [63]. An early case control autopsy study revealed a 
predilection for small coronary arteries or arterioles present in $17 \%$ of SSc against $2 \%$ of controls $(P<0.01)[64]$; this matches the data of a very recent study in which SSc patients had lower myocardial perfusion during adenosine stress compared to controls $(p=0.008)$ implying microvascular myocardial disease[65].

\section{Oxidative Stress and Vascular Manifestations in Systemic Sclerosis}

As mentioned previously ROS and more specifically isoprostanes are oyerproduced in SSc and bear major clinical relevance [66]: 1) isoprostanes inversely correlated with post-occlusion hyperemia, expressed either as raw data $(\mathrm{p}=0.007)$ or as an increase compared to baseline $(p=0.04)$ whereas endothelium-independent response did not change [67]; 2) urinary isoprostane strongly correlated with nail fold morphological capillaroscopic pattern $(p=0.002)$ and lung involvement $(p=0.003)$, showing increasing levels with the progression of pulmonary severity [68];3) similarly serum isoprostanes correlated negatively with pulmonary function (percentage vital capacity and diffusion capacity for carbon monoxide) and positively with renal vascular damage assessed by colour flow Doppler ultrasonography [69]. Among other less specific oxidative stress markers, plasma hydroperoxides correlated with the semiquantitative capillaroscopy rating score $(\mathrm{p}<0.05)[70]$.

\section{Nitrative Stress and Vascular Manifestations in Systemic Sclerosis}

SSc patients also show overproduction of nitrate [71,72] in relation to markers of endothelial damage and disease activity [72]; dcSSc patients display higher plasma concentration of crude plasma NT than patients with $1 \mathrm{CSSc}$, in relation to the severity and the duration of the disease; moreover NT staining is increased in skin biopsy sections from dcSSc compared to $1 \mathrm{cSSc}$ [73]. At variance another study did not detect NT differences between dcSSc and lcSSc disease, though in the whole SSc population NT levels correlated inversely with the carbon monoxide diffusion capacity $(\mathrm{p}<0.02)$ [74]. To gain further insight in on the nitrative stress pathway, histologically graded skin biopsies from 33 patients with SSc (ten grade 0 , ten grade 1, eight grade 2 , and five grade 
3) and eight healthy controls were reacted with antibodies against eNOS and inducible NOS (iNOS) and NT. The degree of staining was assessed using a semi-quantitative system and a staining score was developed for the endothelial cells (EC) of different vessel types in different areas of dermis at all grades. In biopsies from patients with SSc, superficial microvessel ECs showed a peak of eNOS expression in grade 1 skin which fell as the grade increased. By contrast, iNOS staining increased with the grade of skin lesion, a pattern paralleled by endothelial NT detection. These findings suggest that at some point during the progression of the skin lesions, dermal ECs undergo a metabolic switch from constitutional expression of eNOS to cytokine activation of iNOS that, in the presence of adequate substrate availability (arginine) releases up to 1000 fold more $\mathrm{NO} \bullet$ than eNOS; this excess $\mathrm{NO} \bullet$ reacts with $\mathrm{O}^{2} \bullet$ - forming more ONOO- that my nitrate skin proteins as well as contributing to EC malfunction [75]. This has to be reconciled with the notion whereby several stimuli failed to activate iNOS in human $\mathrm{EC}[76]$ whereas iNOS is truly inducible in murine ECs [77]

\section{Human interventional Studies with Agents bearing Antioxidant Properties}

With the knowledge that SSc patients overproduce ROS in relation to specific clinical features, several authors undertook interventional trials with different agents bearing antioxidant properties as indicated below.

\section{Vitamin E and A: mechanisms of action}

Vitamin E ( $\alpha$-tocopherol) is a lipid soluble membrane antioxidant that protects against lipid peroxidation by scavenging free radicals and superoxide[78] though it may also increase intracellular superoxide dismutase and catalase via NF- $\kappa \mathrm{B}$ modulation[79]. Its efficacy in SSc has been tested in isolation or in combination with various agents. Vitamin A (retinol) derives from $\beta$-carotene, a polyunsaturated hydrocarbon present in the hydrophobic domains of LDL, member of the large carotenoid family that includes also abscisic acid and crocetin. As an antioxidant Vitamin A quenches NO2 • and the 
peroxyl radicals: this effect strongly depends on the $\mathrm{O}^{2}$ partial pressure and it is possibly overcome by pro-oxidant toxic effects at the high $\mathrm{O}^{2}$ partial pressure in the lungs. As a transcriptional modulator, Vitamin A (as all-trans-RA) regulates in a dose-dependent manner collagen gene expression in fibroblasts from normal subjects and from SSc patients[80].

\section{Vitamin $\mathbf{E}$ and $\mathrm{A}$ in systemic sclerosis}

A randomized, double-blind, placebo-controlled trial compared the efficacy of 500 or $1000 \mathrm{mg}$ of vitamin $\mathrm{E}$ once daily versus placebo in SSc: after three weeks of treatment neither dose of vitamin $\mathrm{E}$ had any effect on the clinical (blood flow variation in response to cold) or the biochemical outcomes [81]. Vitamin E has been used in combination with vitamin C (a water soluble and chain breaking antioxidant that promotes the regeneration of vitamin E), beta-carotene (two molecules of dietary vitamin A joined together), selenium (cofactor to several intracellular enzymes with antioxidant activity: glutathione peroxidase, thioredoxin reductase and iodothyronine deiodinases), and methionine in a placebo-controlled double-blind crossover study. The efficacy of the above mentioned concoction, "BioAntox", was evaluated on the frequency and the duration of RP attacks, on the thermographic response to a standard cold challenge and on free radical markers in 1cSSc; after the 20-week study period there was no effect on clinical outcomes despite an increase of the levels of antioxidant molecules on active treatment[82]. In a further study vitamin E (800 UI/day) was paired with pentoxyphylline ( $800 \mathrm{mg} /$ day) in a 24 week open-label trial to examine their effect on a possible decrement of the modified Rodnan skin score (from a baseline of at least 15 points), an improvement of ischemic ulcers and laboratory parameters; after 16 weeks the average skin score had decreased from 25.7 to 18.7 and remained such at 24 weeks; however the intervention with two agents limits our understanding of the effect of Vitamin E [83]. Finally, a randomized trial compared intravenous cyclophosphamide $\left(500 \mathrm{mg} / \mathrm{m}^{2}\right.$ of body surface area monthly) combined with vitamin E (400IU/day) and vitamin C (1g/day) versus antioxidant 
vitamins without cyclophosphamide: after six months the skin thickening of SSc patients receiving antioxidants with cyclophosphamide was significantly inferior than that of SSc receiving cyclophosphamide alone but it is not clear how much of the benefit can be ascribed to either vitamin [84]. The topical administration of vitamin E twice weekly, in addition to a standard medication protocol, induced faster pain resolution and healing of digital ulcers in 15 treated SSc patients compared to 12 untreated controls (n $=12)[85]$.

With regards to carotenoids, protracted topical tretinoin resulted in considerable improvement in mouth and facial skin tightening in few patients[86]; etretinate, a lipophilic, aromatic retinoid induced a 75\% skin score decrement in SSc patients at $0.5 \mathrm{mg} / \mathrm{kg}$ per day, in isolation (7 cases) or in combination with other drugs (systemic corticosteroids, immunosuppressants, d-penicillamine, methotrexate, bucillamine and/ or UVA irradiation) (5 cases) compared to 19 SSc patients not receiving etretinate, but only ointments and vasodilators (6 cases) or other drugs (corticosteroids, immunosuppressant) (13 cases)[87].

\section{N-Acetylcysteine: mechanism of action}

Acetylation of the aminoacid L-cysteine yields N-Acetylcysteine (NAC), the direct antioxidant activity of which resides within the thiol group; however, the scavenging effect in vivo depends on the reaction rate of NAC towards the oxidants formed at any given intracellular or extracellular site and on the relative concentrations of antioxidant and oxidant present at any given moment. With this in mind NAC has reasonable direct antioxidant activity against $\mathrm{NO}^{2}$, hypohalous acids deriving from peroxidases and $\mathrm{HOX}$ but negligible activity against $\mathrm{H}^{2} \mathrm{O}^{2}, \mathrm{O}^{2} \bullet-$, and $\mathrm{ONOO}^{-},[88]$. On the other hand NAC behaves as an indirect antioxidant by boosting the intracellular content and consequently the natural antioxidant defence of GSH that has been depleted for any reason. GSH is a tripeptide (c-L-glutamyl-L-cysteinylglycine, GSH) synthesised and maintained at 
elevated $(\mathrm{mM})$ intracellular concentrations[89]. NAC achieves this as a precursor of cystein, the rate-limiting factor in cellular GSH[90]. The latter is as a substrate or cofactor for a large number of cellular antioxidant enzymes: glutathione reductase, glutaredoxin, glutathione peroxidase, peroxiredoxin, glyoxalases 1 and 2, glutathione transferase[91]. Given in acute or chronic regimens NAC significantly replenished the GSH pool in certain organs such as liver, skin, lung, and brain, preventing the damaging effects of GSH impoverishment on these organs. NAC has the ability to restore the intracellular thiol pool that in turn regulates the redox state[92].

\section{N-Acetylcysteine in systemic sclerosis}

A parallel, double-blind, placebo-controlled, prospective study carried out on $22 \mathrm{SSc}$ failed to show any clinical response after 1-year of oral NAC (up to 10g/day) [93]; the inefficacy of NAC via the oral route (1.8 $\mathrm{g}$ daily) on digital blood flow and RP was confirmed in a short tem double-blind, placebo-controlled trial on 42 SSc patients [94]. Converselyone group has consistently shown the benefits of intravenous NAC (15 mg/ $\mathrm{Kg} / \mathrm{h}$ for 5 consecutive hours every 14 days) in the medium term management of SSc: in one open label study carried over 3 years they documented a reduction of attacks and severity of RP and of digital ulcers [95], a reduction of the resistance index of the renal arteries alongside an improvement of the diffusion capacity for carbon monoxide $[96,97]$.

\section{Penicillamine: mechanism of action}

Of the effects that PEN has on collagen metabolism [98] few were exploited in the management of SSc: PEN interferes with collagen biosynthesis, with the formation of intra and inter molecular cross links and accelerates collagen turnover [99-101]. Moreover, PEN seems to have also antioxidant proprieties: it is structurally similar to the $\alpha$-amino acid cysteine but with two methyl groups attached to the same $\alpha$ carbon as the thiol group that can act as an electron donor scavenge free radicals in a way similar to GSH[102]. Elevated ROS beyond that required for the normal biochemical processes 
would deplete the reduced form of PEN as the first line of antioxidant defence against ROS. In turn PEN would lessen the reduced form of glutathione (GSH) because of its lower redox potential and be converted to a GSSG adduct. Under normal circumstances, the GSSG adduct is reduced back to GSH by the action of cellular anti-oxidative enzymes including glutathione reductase and glutathione peroxidase[103].

\section{Penicillaminein systemic sclerosis}

Between 1966 and 1988 several uncontrolled studies, using different dosages and duration of treatment, concluded that PEN decreased skin thickness in patients with systemic sclerosis[104-107] These evidences led other authors to design studies with with more representative samples and more reliable endpoints. The ambiguous results obtained aroused a fervent debate at the beginning of the 2000s, causing various controversies on this topic $[108,109]$. In fact the only one double blind, randomized, prospective study, investigating the effect of low dose (125 mg every other day) and high dose (822 mg daily) of PEN, failed to show any clinical improvement in systemic sclerosis[110] whereas many other observational and retrospective studies [111-113] demonstrated that PEN reduces skin sclerosis, slows new visceral organ involvement and improves 5 years survival. In fact, at a median dose of $750 \mathrm{mg}$ per day, PEN is associated with a statistically significant reduction in skin, renal, cardiac and pulmonary involvement and overall mortality [111-113]. Unfortunately $20 \%$ of patients on PEN developed membranous glomerulopathy with proteinuria with a 40\% mortality [114] and many others developed several autoimmune disorders[115].

\section{Probucol: mechanism of action}

Probucol is a bis-phenol lipophilic lipid-lowering agent that inhibits oxidation of lowdensity lipoproteins from which its antioxidant activity that was initially attributed to its phenol moieties[116]; the latter however do not protect against 2-electron 
oxidation that is instead achieved by the two sulphur moieties of probucol[117]. Probucol increases the expression of $\mathrm{HOl}$ gene and activity in balloon-injured rabbit aorta and rabbit aortic smooth muscle cells[118]: the promoter region of the HO1 gene contains multiple copies of ARE controlled by the redox-sensitive transcription factor Nfr2[119]: the phenol moieties of probucol are involved in this effect[120]. Moreover probucol inhibited lipopolysaccharide-induced nuclear NF$\mathrm{\kappa B}$ activation in paw tissue as well as NF- $\mathrm{\kappa B}$ activity in cultured macrophages indicating that probucol may block the NF-кB transcriptional pathway[121]. Furthermore, probucol inhibits protein argininemethyltransferase I expression, increase dimethylarginine dimethylaminohydrolase activity, reduce the asymmetric dymethil arginine concentration and restore the activity of eNOS in cultured EC[122] whereas in animal models it enhances catalase and glutathione peroxidase activities[123].

\section{Probucol in systemic sclerosis}

One trial compared the efficacy of probucol ( $500 \mathrm{mg} /$ day) or nifedipine (20 mg/day) on the frequency or severity of RP attacks in primary or SSc related RP over a 12 week period: patients on probucol experienced less frequent and less severe attacks of RP than those on nifedipine [124].

\section{Statins: mechanism of action}

Statins are cholesterol lowering drugs that inhibit the enzyme 3-hydroxy-3methylglutaryl-CoA (HMG-CoA) reductase, fundamental step in the synthesis of endogenous cholesterol. Statins are pleiotropic drugs in that apart from lowering cholesterol they have also anti-inflammatory, antioxidant, anti-fibrotic and anti-platelet properties. These pleiotropic effects are due to their ability to suppress pro-oxidant enzymes such as NOX, to induce the nitric endothelial oxide synthase (eNOS) and enhance levels and activity of endogenous antioxidant systems.

Endothelial NOS generates $\mathrm{NO} \cdot$ by converting L-arginine into L-citrulline in the presence of nicotinamide adenine dinucleotide phosphate (NADPH) and other cofactors such as calmodulin, flavin adenine dinucleotide, flavin mononucleotide and tetrahydrobiopterin (BH4)[125]; it maintains arterial vasodilation and exerts 
anti-inflammatory, anti-proliferative and antithrombotic activities. Statins regulate eNOS expression through several mechanisms. One is the inhibition of mavelonate formation, the precursor of isoprenoids such as geranyl-geranyl-pyrophosphate (GGPP) and Farnesyl-pyrophosphate (FPP). The GGPP activates the Rho A pathway that destabilizes the eNOS mRNA[126], and inhibits the PI3K/Akt pathway, preventing thus the phosphorylation of eNOS[127]. FPP, through the sterol regulatory building protein reduces the transcription of caveolin-1 and activates eNOS[128].

Statins have a dual antioxidants capacity: they can suppress pro-oxidant enzymes and activate antioxidant ones. With regards to the former capacity, atorvastatin down regulated NOX1 expression and Rac1 membrane translocation in VSMCs resulting in reduced ROS generation[125,129]. In a reverse fashion, withdrawal of cerivastatin from VSMCs in culture induced the translocation of Racl to the membrane, with a subsequent activation of NOX complexes and increase in ROS production[130]. Moreover, porcine coronary arteries exposed to high glucose levels generated increased ROS that may was suppressed by statins through reduction of $2^{2}$ phox mRNA levels[131]. In the cellular membrane, NOX oxidase co-localizes with ceramide and acid sphingomyelinase to form membrane rafts; statin treatment prevents the oxidised low density lipoprotein induced formation of membrane rafts consequently reducing ROS generation from human coronary artery endothelial cells[132]. In a rat model, statin suppressed NOX activity through a mevalonate-dependent prevention of Rac activation, favouring increased NO bio-availability and improved endothelial function[133]. In humans, short-term treatment with atorvastatin rapidly inhibits NOX activity hence ROS generation in saphenous venous grafts from patients undergoing coronary artery bypass independently of the lipid lowering effect of the drug[134].

With regards to stimulating anti-oxidant enzymes, simvastatin partially restored renal levels of the three major cellular antioxidant defence systems (SOD, GSH-Px, and catalase) in diabetic animals $[135,136]$ whereas in rats chronically treated with the eNOS inhibitor L-NAME statins improve endothelial function by increasing SOD levels[137]. Rosuvastatin antagonizes the deleterious effects of Ang II on the vascular system by 
down regulating the expression of NOX4 and increasing the expression of SOD[138]. Atorvastatin increase the gene expression and activity of catalase in aortic VSMCs from rats and in senescent HUVECs[125].

Furthermore, by inhibiting pro-oxidant enzymes and restoring eNOS coupling, statins act also at transcriptional level: in fact, reduction of ROS generation prevents ROS induction of NFkB; in addition statins increase the levels of the inhibitor $\operatorname{IkB} \alpha$ and decrease those of IKK, reducing the binding capacity of NFkB that does not engage in the transcription of genes coding for pro-inflammatory cytokines[139],

\section{Statins in systemic sclerosis}

Stemming from this evidence, several studies investigated the protective role of statins in SSc and a recent meta-analysis determined that statins treatment is associated with significant biochemical and clinical improvements[140]. All studies included in the final analysis showed a significant reduction of Interleukin-6 (IL-6), E-selectin, vascular endothelial growth factor (VEGF), endothelin 1, and basic fibroblast growth factor[140-147] Only one study measured NO that significantly increased following treatment with simvastatin at a dose of $20 \mathrm{mg}$ daily for 12 weeks[140]. Four of the studies in the meta-analysis evaluated flow mediated vasodilation. Of these, three cohort studies showed a significant improvement in endothelium dependent dilatation though the only randomized control trial present in the meta-analysis not revealed any improvement in endothelium dependent and independent vasodilatation after 8 weeks of treatment with $20 \mathrm{mg}$ of Simvastatin. In all the studies considered in the meta-analysis, no significant improvements was shown in regard of other vascular parameters, such as endothelium independent vasodilatation, arterial stiffness, ankle/brachial index or carotid intimal medial thickness.

\section{Animal and in vitro Studies with Agents bearing Antioxidant Properties}

\section{Vitamin E}


Conditioned media from SSc patients and isoprostanes inhibited endothelial cell tube formation in vitro, the equivalent of angiogenesis in vivo, via activation of the thromboxane A2 receptor and the Rho-associated kinase pathways that suppresses vascular endothelial growth factor (VEGF) activity. The addition of vitamin E increased cell tube formation [148].

\section{Edaravone}

Edaravone is a phenolic compound used in neurology to limit hydroxyl radicaldependent and radical-independent peroxidation of brain lipids [149]; it quenches ROS generated from neutrophil NOX and by mitochondria[150]rather than by inhibiting neutrophil function[151]. In animal models of ischemia-reperfusion edaravone suppresses the oxidative/inflammatory response secondary to ROS [152]. In the tight skin mouse and in the bleomycin-induced SSc mouse edavarone reduced skin and lung fibrosis alongside the reduction of fibrogenic cytokines and ONOO [153].

\section{Lipoic acid}

Alpha-lipoic acid (LA) is a naturally occurring dithiol compound enzymatically synthesized in mitochondria from octanoic acid[154]. From the free radical perspective, in cells containing mitochondria, LA is reduced to dihydrolipoic acid (DHLA) via an NADPH-dependent reaction with lipoamide dehydrogenase whereas in cells lacking mitochondria LA is reduced to DHLA via thioredoxin reductase [155]. Two relevant aspects of LA are that both its oxidized and reduced forms are powerful antioxidants and being amphiphilic ad that LA exerts its antioxidant effects in the cytosol as well as in the plasma membrane[156]. In particular LA scavenges hydroxyl radicals and hypochlorous acid and prevents protein carbonyl formation but most importantly it neutralizes free radicals without becoming one itself $[157,158]$. 
Another relevant aspect of LA is its ability to reduce the oxidized forms of other antioxidants such as GSH, vitamin C and E. As an intracellular antioxidant, GSH buffers the thiol redox state: this requires a steady intracellular level of GSH either by substrate availability or by the transcriptional regulation of the GSH gene[159]. Accordingly LA increases cysteine uptake[160] reducing thus the ratio of cystine to cysteine (as cysteine is the rate-limiting substrate for this reaction) [161] and activates Nrf-2 that mediates the gene expression and synthesis of GSH[159].

Moreover LA regenerates vitamin E either directly by reacting with tocopheroxyl radical or indirectly by reducing dehydroascorbate, which in turn reduces alpha tocopherol. LA also reduces ubiquinone to ubiquinol, an essential component of the mitochondrial electron transport chain[158]. A stable availability of intracellular GSH prevents the age related oxidation of the sulphur amino acids cysteine and methionine, maintaining them in a reduced form[162] LA has regulatory effects on gene transcription: apart its effect of Nrf-2, LA inhibits I $\kappa \mathrm{B}$ degradation and NF- $\kappa \mathrm{B}-$ dependent gene expression independently of its antioxidant function[157,163]. Finally because of its two thiol groups, LA chelates several divalent metal ions in vitro and can form stable complexes with $\mathrm{Fe}^{2++}$ [164] minimising thus iron induced oxidative stress[165]. We know thattotal plasma and dermal fibroblast thiols are reduced in SSc [148].

In vitro experiments have shown that LA and its metabolite dihydrolipoic acid (DHLA) behave as antioxidants in dermal fibroblasts in that they quench the production of ONOO- that in turn is accompanied by a reduction of PDGFR phosophorilation and consequently lower expression of Col I; the authors suggest that LA and DHLA may act on redox-sensitive transcription factors that control the expression of phosphatases though their data cannot be extrapolated to the in vivo scenario [166].

\section{Pantethine}

As mentioned earlier pantethine is a vasculoprotective compound made up of two pantetheines joined by a disulphide bridge produced from vitamin B5 (pantothenic acid) 
by the addition of cysteamine; the vanin/pantetheinase pathway [48] may hydrolyse pantethine into pantothenic acid that is profibrotic and cysteamine that is pro-oxidant. Over activation of the vanin-1/pantetheinase pathway occurs in wild-type BALB/c mice with hypochlorous acid (HOCl)-induced SSc [167]. Pantethine administration restored the production of gluthatione and decreased the generation of ONOO- in fibroblasts and EC alongside a decrease in skin and lung fibrosis [167].

\section{Asiatic acid}

Asiatic acid is a pentacyclic triterpenoid extracted from Centella asiatica, a herbaceous perennial plant from the family of Apiaceae: it inhibits TGF- $\beta 1$-induced collagen expression in human keloid fibroblasts, via PPAR-gamma activation [168]. In the hypochlorous acid-induced murine model of systemic sclerosis, asiatic acid alleviated pulmonary fibrosis and slowed disease progression compared to untreated mice. Moreover, trans-differentiation of fibroblasts into myofibroblasts was significantly reduced in the lungs of SSc mice treated with asiatic acid[169].

\section{Tanshinone IIA}

Tanshinone IIA is a natural diterpene quinone with antioxidant and anti-inflammatory properties, isolated from the root of Salvia miltiorrhiza. It exerted inhibitory effects on IL-17-induced ERK phosphorylation and functional activation (proliferation, collagen type I and III synthesis, and migration) of dermal vascular smooth muscle cells isolated from SSc patients[170].

\section{Crocetin}

Crocetin is an apocarotenoid dicarboxylic acid extracted from Crocus flowers and Gardenia jasminoides fruits. Crocetin inhibited the proliferation of normal and SSc fibroblasts and the trans-differentiation of SSc fibroblasts into myofibroblasts; in the bleomicin mouse model of SSc repeated intraperitoneal injection of crocetin alleviated 
skin and lung fibrosis in association with decreased levels of mRNAs for type 1 collagen and endothelin-1 in skin and lung[171].

\section{Epigallocatechin-3-gallate}

Epigallocatechin-3-gallate (EGCG) is the ester of epigallocatechin and gallic acid (trihydroxybenzoic acid), a type of phenolic acid. EGCG is a polyphenol found in high content in the leaves of green tea and white tea. Orally administered EGCG is poorly absorbed. EGCG down-regulates, in a dose-dependent manner, basal levels of type I collagen and TGF- $\beta$-stimulated production of type I collagen, fibronectin and connective tissue growth factor (CTGF) in fibroblasts isolated from normal subjects and patients affected by SSc. More interestingly EGCG suppressed TGF- $\beta$-induced ROS production in all fibroblasts and inhibited NF- $\kappa \mathrm{B}$ actiyation in response to TGF- $\beta$ or PDGF-BB[172,173].

\section{Curcumin}

Curcumin is a phenolic diarylheptanoid deriving the spice turmeric (Curcuma longa). Curcumin protected rats against lung fibrosis induced by bleomycin[174] and induced apoptosis in scleroderma lung fibroblasts, but not in normal lung fibroblasts[175]. Curcumin acted via induction of the Nrf2/ARE pathway, increasing the expression of intracellular detoxifying enzymes in fibroblasts[176]. Furthermore, curcumin exerted a marked inhibitory activity on TGF- $\beta$ signaling in SSc fibroblasts, by counteracting TGF- $\beta$-induced phosphorylation of Smad2, but not Smad3[177]. Unfortunately the potential utility of curcumin as a therapeutic agent is limited by its chemical instability, insolubility in water,[178] and poor bioavailability after oral administration[179]. 


\section{Appraising the Complexity of Antioxidant Treatment}

Before considering treatment with antioxidant agents it must be appreciated that ROS and RNS develop in different intracellular compartments within different cell types and in different organs before occurring systemically [180]. From the previous paragraphs it appears that intracellular NOX and extracellular TGF- $\beta$ have reciprocal effects: NOX4 mediates TGF- $\beta$ induced pro-fibrotic responses [181] whereas TGF- $\beta$ specifically increases NOX4 gene expression [182]. In keeping with the first pathway treatment with small interfering RNA against NOX4 prevented the expression of TGF- $\beta$ target genes such as fibronectin, collagen I and connective tissue growth factor [142]; with regards to the second pathway TGF- $\beta$ upregulates NOX4 expression hence ROS via the classical Smad2/3 and the PI3K intracellular pathways[183]. Moreover, intracellular ROS may increase JNK and p38 activation aiding further the effect of TGF- $\beta$-induced signalling [184] whereas extracellular ROS may directly convert inactive TGF- $\beta$ to its active form, a crucial step in TGF- $\beta$ signalling [185]: in fact HNN, the major reactive aldehyde formed during lipid peroxidation, when added to cultured macrophages up-regulates the expression and release of TGF- $\beta[186]$. Finally TLR4 may be sense ROS[20] and mediate NFkB activation via non-receptor tyrosine kinases[19] and via inflammasomes [29]; ROS/RNS generated in the course of oxidation and inflammation may also induce post-translational modifications in connective tissue proteins that in turn may act as danger signals for TLR4 and further perpetuate the production of TGF $\beta$ hence of fibrosis[18]. It remains to be ascertained whether these in vitro pathways are also active in vivo. Apart from this complex interplay, antioxidant agents, including vitamins, react with $\mathrm{O}^{2} \bullet-$ almost one billion times slower than $\mathrm{NO}^{\bullet}$; this means that the reaction of $\mathrm{O}^{2} \bullet-$ with $\mathrm{NO}^{*}$ is energetically favoured leading to a constant loss of bioavailable NO• 


\section{Targeting Nfr2e}

To restore or to increase the intracellular antioxidant environment seems an attractive goal: unfortunately only a limited number of agents able to induce the transcription of $\mathrm{Nfr} 2$ and enhance the synthesis of detoxifying enzymes. Amongst these curcumin [176] probucol [118] and LA[159]seem suitable candidates. Curcumin however has limited pharmaco dynamic and pharmaco kinetic properties [178,179], probucol has the added benefit of suppressing NF-кB activation [121], whereas LA not only activates Nrf-2 [159], but increases cysteine uptake [160], maintains in reduced form other intracellular antioxidants including vitamin E [159] and inhibits NF- $\mathrm{BB}$-dependent gene expression $[144,150]$ making it an all-round and desirable antioxidant agent.

\section{Targeting NAPDH oxidase}

Silencing NOX4 with small inhibitory RNA improved bleomycin induced lung fibrosis in the specific mouse model[187]; GKT-137831, a specific NOX1 and NOX4 inhibitor under clinical development[188] decreases CCN2 and $\alpha$-SMA expression and collagen gel interaction in SSc fibroblasts[189]. Azithromycin (AZM), apart from its antibiotic activity, exerts antioxidant and antifibrotic properties in the bleomycin mouse model of lung fibrosis[190]; in particular AZM degrades the proteasome activating NOX4, preventing the TGF $\beta$-induced myofibroblast differentiation and limiting lung fibrosis[191]. Diphenyleneiodonium, a pan-Nox inhibitor, inhibited gene expression of collagen type and fibronectin in human dermal fibroblasts and limited skin fibrosis and myofibroblast activation in the bleomycin mouse model [192].

Outside SSc, atorvastatin and rosuvastatin have the capacity to inhibit the NOX system [193,194]; in a mouse model of diabetes probucol downregulated NOX expression[195] and in human renal proximal tubular epithelial cells it prevented epithelial-mesenchymal transition [196] though the latter is debated[197]; it is envisaged that probucol might have similar effect of SSc fibroblasts. LA may dampen NOX activity either when being reduced [198] or via inhibition of the signalling pathways leading to NOXactivation [199]. 


\section{Concluding Remarks}

According to their lipophilic/hydrophilic nature, their dose and their route of administration, antioxidants or agents with antioxidant properties may achieve in vivo different plasma, tissue or intracellular level, and for each compartment the therapeutic level may vary. On the other hand, one issue is to quench extracellular or intracellular ROS/RNS, another is to target and switch off the genes and/or the enzymatic systems producing them. In this respect statins, probucol and LA may have something new to offer in the management of SSc. Knowledge of the cellular/sub-cellular localisation of potential target enzymes, of the equilibrium constant of the biochemical reactions involved and of the pharmacokinetics and pharmacodynamics of different antioxidants are necessary pre-requisites for the planning of randomised clinical trials. These might explore different doses and/or combinations of new and old antioxidants with adequate follow-up, taking into account the timing of the intervention with regards to disease duration, disease activity and organ involvement. The heterogeneity of the SSc populations to be enrolled ought to be overcome by joining forces in multicenter trials, possibly free from the influence of the pharmaceutical industry. It is envisaged that an expert in free radical chemistry and biology should be included amongst the team members to adyice less savvy clinicians on the intricacies of redox biology in vivo. The new information accrued over the last decade on ROS/RNS and their possible manipulation at gene level makes this an interesting time for antioxidant intervention in a disease such as SSc that still defies conventional treatments.

Acknowledgments: supported by www.fondazioneaps.org, an Italian Registered Charity

Disclosure statement: none of the authors declare any conflict of interest. 


\section{REFERENCES}

[1] Pattanaik D, Brown M, Postlethwaite AE. Vascular involvement in systemic sclerosis (scleroderma). J Inflamm Res 2011;4:105-25.

[2] Bhattacharyya S, Wei J, Varga J. Understanding fibrosis in systemic sclerosis: shifting paradigms, emerging opportunities. Nat Rev Rheumatol 2011;8(1):42-54.

[3] Nourooz-Zadeh J. Key issues in F2-isoprostane analysis. Biochem Soc Trans 2008;36(Pt 5):1060-5.

[4] Panieri E, Santoro MM. ROS signaling and redox biology in endothelial cells. Cell Mol Life Sci 2015;72(17):3281-303.

[5] Abello N, Kerstjens HA, Postma DS, Bischoff R. Protein tyrosine nitration: selectivity, physicochemical and biological consequences, denitration, and proteomics methods for the identification of tyrosine-nitrated proteins. J Proteome Res 2009;8(7):3222-38.

[6] Villacorta L, Gao Z, Schopfer FJ, Freeman BA, Chen YE. Nitro-fatty acids in cardiovascular regulation and diseases: characteristics and molecular mechanisms. Front Biosci (Landmark Ed) 2016;21:873-89.

[7] Wang W, Li C, Yang T. Protection of nitro-fatty acid against kidney diseases. Am J Physiol Renal Physiol 2016;310(8):F697-F704.

[8] Dadoniene J, Cypiene A, Ryliskyte L, Rugiene R, Ryliskiene K, Laucevicius A. Skin Autofluorescence in Systemic Sclerosis Is Related to the Disease and Vascular Damage: A Cross-Sectional Analytic Study of Comparative Groups. Dis Markers 2015;2015:837470.

[9] van Bon L, Cossu M, Loof A, Gohar F, Wittkowski H, Vonk M, Roth J, van den Berg W, van Heerde W, Broen JC and others. Proteomic analysis of plasma identifies the Toll-like receptor agonists S100A8/A9 as a novel possible marker for systemic sclerosis phenotype. Ann Rheum Dis 2014;73(8):1585-9.

[10] Brown DI, Griendling KK. Nox proteins in signal transduction. Free Radic Biol Med 2009;47(9):1239-53.

[11] Piera-Velazquez S, Jimenez SA. Role of cellular senescence and NOX4-mediated oxidative stress in systemic sclerosis pathogenesis. Curr Rheumatol Rep 2015; 17(1):473.

[12] Sambo P, Baroni SS, Luchetti M, Paroncini P, Dusi S, Orlandini G, Gabrielli A. Oxidative stress in scleroderma: maintenance of scleroderma fibroblast phenotype by the constitutive up-regulation of reactive oxygen species generation through the NADPH oxidase complex pathway. Arthritis Rheum 2001;44(11):2653-64.

[13] Ellmark SH, Dusting GJ, Fui MN, Guzzo-Pernell N, Drummond GR. The contribution of Nox4 to NADPH oxidase activity in mouse vascular smooth muscle. Cardiovasc Res 2005;65(2):495-504.

[14] Breton-Romero R, Lamas S. Hydrogen peroxide signaling in vascular endothelial cells. Redox Biol 2014;2:529-34.

[15] Sambo P, Jannino L, Candela M, Salvi A, Donini M, Dusi S, Luchetti MM, Gabrielli A. Monocytes of patients wiht systemic sclerosis (scleroderma 
spontaneously release in vitro increased amounts of superoxide anion. J Invest Dermatol 1999;112(1):78-84.

[16] Amico D, Spadoni T, Rovinelli M, Serafini M, D'Amico G, Campelli N, Svegliati Baroni S, Gabrielli A. Intracellular free radical production by peripheral blood T lymphocytes from patients with systemic sclerosis: role of NADPH oxidase and ERK1/2. Arthritis Res Ther 2015;17:68.

[17] Gill R, Tsung A, Billiar T. Linking oxidative stress to inflammation: Toll-like receptors. Free Radic Biol Med 2010;48(9):1121-32.

[18] Bhattacharyya S, Kelley K, Melichian DS, Tamaki Z, Fang F, Su Y, Feng G, Pope RM, Budinger GR, Mutlu GM and others. Toll-like receptor 4 signaling augments transforming growth factor-beta responses: a novel mechanism for maintaining and amplifying fibrosis in scleroderma. Am J Pathol 2013;182(1):192-205.

[19] Karki R, Igwe OJ. Toll-like receptor 4-mediated nuclear factor kappa B activation is essential for sensing exogenous oxidants to propagate and maintain oxidative/nitrosative cellular stress. PLoS One 2013;8(9):e73840.

[20] Mancek-Keber M, Frank-Bertoncelj M, Hafner-Bratkovic I, Smole A, Zorko M, Pirher N, Hayer S, Kralj-Iglic V, Rozman B, Hc N and others. Toll-like receptor 4 senses oxidative stress mediated by the oxidation of phospholipids in extracellular vesicles. Sci Signal 2015;8(381):ra60.

[21] Stifano G, Affandi AJ, Mathes AL, Rice LM, Nakerakanti S, Nazari B, Lee J, Christmann RB, Lafyatis R. Chronic Toll-like receptor 4 stimulation in skin induces inflammation, macrophage activation, transforming growth factor beta signature gene expression, and fibrosis. Arthritis Res Ther 2014;16(4):R136.

[22] Fang F, Marangoni RG, Zhou X, Yang Y, Ye B, Shangguang A, Qin W, Wang W, Bhattacharyya S, Wei J and others. Toll-like Receptor 9 Signaling Is Augmented in Systemic Sclerosis and Elicits Transforming Growth Factor beta-Dependent Fibroblast Activation. Arthritis Rheumatol 2016;68(8):1989-2002.

[23] Piera-Velazquez S, Makul A, Jimenez SA. Increased expression of NAPDH oxidase 4 in systemic sclerosis dermal fibroblasts: regulation by transforming growth factor beta. Arthritis Rheumatol 2015;67(10):2749-58.

[24] Guo W, Saito S, Sanchez CG, Zhuang Y, Gongora Rosero RE, Shan B, Luo F, Lasky JA. TGF-betal stimulates HDAC4 nucleus-to-cytoplasm translocation and NADPH oxidase 4-derived reactive oxygen species in normal human lung fibroblasts. Am J Physiol Lung Cell Mol Physiol 2017;312(6):L936-L944.

[25] Bauernfeind FG, Horvath G, Stutz A, Alnemri ES, MacDonald K, Speert D, Fernandes-Alnemri T, Wu J, Monks BG, Fitzgerald KA and others. Cutting edge: NF-kappaB activating pattern recognition and cytokine receptors license NLRP3 inflammasome activation by regulating NLRP3 expression. J Immunol 2009;183(2):787-91.

[26] Bauernfeind F, Bartok E, Rieger A, Franchi L, Nunez G, Hornung V. Cutting edge: reactive oxygen species inhibitors block priming, but not activation, of the NLRP3 inflammasome. J Immunol 2011;187(2):613-7.

[27] Abais JM, Xia M, Zhang Y, Boini KM, Li PL. Redox regulation of NLRP3 inflammasomes: ROS as trigger or effector? Antioxid Redox Signal 2015;22(13):1111-29. 
[28] Martinez-Godinez MA, Cruz-Dominguez MP, Jara LJ, Dominguez-Lopez A, Jarillo-Luna RA, Vera-Lastra O, Montes-Cortes DH, Campos-Rodriguez R, Lopez-Sanchez DM, Mejia-Barradas CM and others. Expression of NLRP3 inflammasome, cytokines and vascular mediators in the skin of systemic sclerosis patients. Isr Med Assoc J 2015;17(1):5-10.

[29] Artlett CM, Sassi-Gaha S, Rieger JL, Boesteanu AC, Feghali-Bostwick CA, Katsikis PD. The inflammasome activating caspase 1 mediates fibrosis and myofibroblast differentiation in systemic sclerosis. Arthritis Rheum 2011;63(11):3563-74.

[30] Artlett CM, Sassi-Gaha S, Hope JL, Feghali-Bostwick CA, Katsikis PD. Mir-155 is overexpressed in systemic sclerosis fibroblasts and is required for NLRP3 inflammasome-mediated collagen synthesis during fibrosis. Arthritis Res Ther 2017;19(1):144.

[31] Leinonen HM, Kansanen E, Polonen P, Heinaniemi M, Levonen AL, Role of the Keap1-Nrf2 pathway in cancer. Adv Cancer Res 2014;122:281-320.

[32] Hennig P, Garstkiewicz M, Grossi S, Di Filippo M, French LE, Beer HD. The Crosstalk between Nrf2 and Inflammasomes. Int J Mol Sci 2018;19(2).

[33] Brewer AC, Murray TV, Arno M, Zhang M, Anilkumar NP, Mann GE, Shah AM. Nox4 regulates Nrf2 and glutathione redox in cardiomyocytes in vivo. Free Radic Biol Med 2011;51(1):205-15.

[34] Schroder K, Zhang M, Benkhoff S, Mieth A, Pliquett R, Kosowski J, Kruse C, Luedike P, Michaelis UR, Weissmann N and others. Nox4 is a protective reactive oxygen species generating vascular NADPH oxidase. Circ Res 2012;110(9):1217-25.

[35] Breton-Romero R, Gonzalez de Orduna C, Romero N, Sanchez-Gomez FJ, de Alvaro C, Porras A, Rodriguez-Pascual F, Laranjinha J, Radi R, Lamas $\mathrm{S}$. Critical role of hydrogen peroxide signaling in the sequential activation of p38 MAPK and eNOS in laminar shear stress. Free Radic Biol Med 2012;52(6):1093-100.

[36] Jiang F, Liu GS, Dusting GJ, Chan EC. NADPH oxidase-dependent redox signaling in TGF-beta-mediated fibrotic responses. Redox Biol $2014 ; 2: 267-72$.

[37] Lyle AN, Deshpande NN, Taniyama Y, Seidel-Rogol B, Pounkova L, Du P, Papaharalambus C, Lassegue B, Griendling KK. Poldip2, a novel regulator of Nox 4 and cytoskeletal integrity in vascular smooth muscle cells. Circ Res 2009; 105(3):249-59.

[38] Mittal M, Roth M, Konig P, Hofmann S, Dony E, Goyal P, Selbitz AC, Schermuly RT, Ghofrani HA, Kwapiszewska G and others. Hypoxiadependent regulation of nonphagocytic NADPH oxidase subunit NOX4 in the pulmonary vasculature. Circ Res 2007;101(3):258-67.

[39] Pierce GF, Mustoe TA, Altrock BW, Deuel TF, Thomason A. Role of plateletderived growth factor in wound healing. J Cell Biochem 1991;45(4):319-26.

[40] Trojanowska M. Role of PDGF in fibrotic diseases and systemic sclerosis. Rheumatology (Oxford) 2008;47 Suppl 5:v2-4.

[41] Gay S, Jones RE, Jr., Huang GQ, Gay RE. Immunohistologic demonstration of platelet-derived growth factor (PDGF) and sis-oncogene expression in scleroderma. J Invest Dermatol 1989;92(2):301-3. 
[42] Baroni SS, Santillo M, Bevilacqua F, Luchetti M, Spadoni T, Mancini M, Fraticelli P, Sambo P, Funaro A, Kazlauskas A and others. Stimulatory autoantibodies to the PDGF receptor in systemic sclerosis. N Engl J Med 2006;354(25):2667-76.

[43] Bae YS, Sung JY, Kim OS, Kim YJ, Hur KC, Kazlauskas A, Rhee SG. Plateletderived growth factor-induced $\mathrm{H}(2) \mathrm{O}(2)$ production requires the activation of phosphatidylinositol 3-kinase. J Biol Chem 2000;275(14):10527-31.

[44] Kawaguchi Y, Takagi K, Hara M, Fukasawa C, Sugiura T, Nishimagi E, Harigai M, Kamatani N. Angiotensin II in the lesional skin of systemic sclerosis patients contributes to tissue fibrosis via angiotensin II type 1 receptors. Arthritis Rheum 2004;50(1):216-26.

[45] Lee DY, Wauquier F, Eid AA, Roman LJ, Ghosh-Choudhury G, Khazim K Block K, Gorin Y. Nox4 NADPH oxidase mediates peroxynitrite-dependent uncoupling of endothelial nitric-oxide synthase and fibronectin expression in response to angiotensin II: role of mitochondrial reactive oxygen species. J Biol Chem 2013;288(40):28668-86.

[46] Luo JY, Liu X, Jiang M, Zhao HP, Zhao JJ. Oxidative stress markers in blood in systemic sclerosis: A meta-analysis. Mod Rheumatol 2017;27(2):306-314.

[47] Ames PRJ, Merashli M, Bucci T, Norouz-Zadeh J. Isoprostane in systemic sclerosis: A systematic review and meta-analysis. Mod Rheumatol 2018:1-6.

[48] Rommelaere S, Millet V, Gensollen T, Bourges C, Eeckhoute J, Hennuyer N, Bauge E, Chasson L, Cacciatore I, Staels B and others. PPARalpha regulates the production of serum Vanin-1 by liver. FEBS Lett 2013;587(22):3742-8.

[49] Lebo RV, Kredich NM. Inactivation of human gamma-glutamylcysteine synthetase by cystamine. Demonstration and quantification of enzyme-ligand complexes. J Biol Chem 1978;253(8):2615-23.

[50] Calkins MJ, Townsend JA, Johnson DA, Johnson JA. Cystamine protects from 3nitropropionic acid lesioning via induction of nf-e 2 related factor 2 mediated transcription. Exp Neurol 2010;224(1):307-17.

[51] Kavian N, Mehlal S, Marut W, Servettaz A, Giessner C, Bourges C, Nicco C, Chereau C, Lemarechal H, Dutilh MF and others. Imbalance of the Vanin-1 Pathway in Systemic Sclerosis. J Immunol 2016;197(8):3326-3335.

[52] Cutolo M, Sulli A, Smith V. Assessing microvascular changes in systemic sclerosis diagnosis and management. Nat Rev Rheumatol 2010;6(10):578-87.

[53] Altorok N, Wang Y, Kahaleh B. Endothelial dysfunction in systemic sclerosis. Curr Opin Rheumatol 2014;26(6):615-20.

[54] Au K, Singh MK, Bodukam V, Bae S, Maranian P, Ogawa R, Spiegel B, McMahon M, Hahn B, Khanna D. Atherosclerosis in systemic sclerosis: a systematic review and meta-analysis. Arthritis Rheum 2011;63(7):2078-90.

[55] Meiszterics Z, Timar O, Gaszner B, Faludi R, Kehl D, Czirjak L, Szucs G, Komocsi A. Early morphologic and functional changes of atherosclerosis in systemic sclerosis-a systematic review and meta-analysis. Rheumatology (Oxford) 2016;55(12):2119-2130.

[56] Faccini A, Agricola E, Oppizzi M, Margonato A, Galderisi M, Sabbadini MG, Franchini S, Camici PG. Coronary microvascular dysfunction in asymptomatic 
patients affected by systemic sclerosis - limited vs. diffuse form. Circ J 2015;79(4):825-9.

[57] Rollando D, Bezante GP, Sulli A, Balbi M, Panico N, Pizzorni C, Negrini S, Brunelli C, Barsotti A, Cutolo $\mathrm{M}$ and others. Brachial artery endothelialdependent flow-mediated dilation identifies early-stage endothelial dysfunction in systemic sclerosis and correlates with nailfold microvascular impairment. J Rheumatol 2010;37(6):1168-73.

[58] Hettema ME, Bootsma H, Kallenberg CG. Macrovascular disease and atherosclerosis in SSc. Rheumatology (Oxford) 2008;47(5):578-83.

[59] Merkel PA, Herlyn K, Martin RW, Anderson JJ, Mayes MD, Bell P, Korn JH, Simms RW, Csuka ME, Medsger TA, Jr. and others. Measuring disease activity and functional status in patients with scleroderma and Raynaud's phenomenon. Arthritis Rheum 2002;46(9):2410-20.

[60] Chung L, Fiorentino D. Digital ulcers in patients with systemic sclerosis Autoimmun Rev 2006;5(2):125-8.

[61] Nihtyanova SI, Brough GM, Black CM, Denton CP. Clinical burden of digital vasculopathy in limited and diffuse cutaneous systemic sclerosis. Ann Rheum Dis 2008;67(1):120-3.

[62] Avina-Zubieta JA, Man A, Yurkovich M, Huang K, Sayre EC, Choi HK. Early Cardiovascular Disease After the Diagnosis of Systemic Sclerosis. Am J Med 2016;129(3):324-31.

[63] Chu SY, Chen YJ, Liu CJ, Tseng WC, Lin MW, Hwang CY, Chen CC, Lee DD, Chen TJ, Chang YT and others. Increased risk of acute myocardial infarction in systemic sclerosis: a nationwide population-based study. Am J Med 2013;126(11):982-8.

[64] D'Angelo WA, Fries JF, Masi AT, Shulman LE. Pathologic observations in systemic sclerosis (scleroderma). A study of fifty-eight autopsy cases and fifty-eight matched controls. Am J Med 1969;46(3):428-40.

[65] Gyllenhammar T, Kanski M, Engblom H, Wuttge DM, Carlsson M, Hesselstrand $\mathrm{R}$, Arheden H. Decreased global myocardial perfusion at adenosine stress as a potential new biomarker for microvascular disease in systemic sclerosis: a magnetic resonance study. BMC Cardiovasc Disord 2018;18(1):16.

[66] Stein CM, Tanner SB, Awad JA, Roberts LJ, 2nd, Morrow JD. Evidence of free radical-mediated injury (isoprostane overproduction) in scleroderma. Arthritis Rheum 1996;39(7):1146-50.

[67] Cracowski JL, Kom GD, Salvat-Melis M, Renversez JC, McCord G, Boignard A, Carpentier PH, Schwedhelm E. Postocclusive reactive hyperemia inversely correlates with urinary 15-F2t-isoprostane levels in systemic sclerosis. Free Radic Biol Med 2006;40(10):1732-7.

[68] Volpe A, Biasi D, Caramaschi P, Mantovani W, Bambara LM, Canestrini S, Ferrari M, Poli G, Degan M, Carletto A and others. Levels of F2-isoprostanes in systemic sclerosis: correlation with clinical features. Rheumatology (Oxford) 2006;45(3):314-20.

[69] Ogawa F, Shimizu K, Muroi E, Hara T, Hasegawa M, Takehara K, Sato S. Serum levels of 8-isoprostane, a marker of oxidative stress, are elevated in patients with systemic sclerosis. Rheumatology (Oxford) 2006;45(7):815-8.

[70] Riccieri V, Spadaro A, Fuksa L, Firuzi O, Saso L, Valesini G. Specific oxidative stress parameters differently correlate with nailfold capillaroscopy 
changes and organ involvement in systemic sclerosis. Clin Rheumatol 2008;27(2):225-30.

[71] Kahaleh BM PSF, Cerinic MM, Stefanovic Racic M, Ignarro L. Study of endothelial dependent relaxation in scleroderma. Arthritis Rheum 1993;36((Suppl.): B233).

[72] Yamamoto T, Katayama I, Nishioka K. Nitric oxide production and inducible nitric oxide synthase expression in systemic sclerosis. J Rheumatol 1998;25(2):314-7.

[73] Dooley A, Gao B, Bradley N, Abraham DJ, Black CM, Jacobs M, Bruckdorfer KR. Abnormal nitric oxide metabolism in systemic sclerosis: increased levels of nitrated proteins and asymmetric dimethylarginine. Rheumatology (Oxford) 2006;45(6):676-84.

[74] Shimizu K, Ogawa F, Muroi E, Hara T, Komura K, Bae SJ, Sato S. Increased serum levels of nitrotyrosine, a marker for peroxynitrite production, in systemic sclerosis. Clin Exp Rheumatol 2007;25(2):281-6.

[75] Cotton SA, Herrick AL, Jayson MI, Freemont AJ. Endothelial expression of nitric oxide synthases and nitrotyrosine in systemic sclerosis skin. J Pathol 1999;189(2):273-8.

[76] Dreger H, Ludwig A, Weller A, Baumann G, Stangl V, Stangl K. Epigenetic suppression of iNOS expression in human endothelial cells: A potential role of Ezh2-mediated H3K27me3. Genomics 2016;107(4):145-9.

[77] Balligand JL, Ungureanu-Longrois D, Simmons WW, Kobzik L, Lowenstein CJ, Lamas S, Kelly RA, Smith TW, Michel T. Induction of NO synthase in rat cardiac microvascular endothelial cells by IL-1 beta and IFN-gamma. Am J Physiol 1995;268(3 Pt 2):H1293-303.

[78] Lass A, Sohal RS. Effect of coenzyme Q(10) and alpha-tocopherol content of mitochondria on the production of superoxide anion radicals. FASEB J 2000;14(1):87-94.

[79] Nakamura YK, Omaye ST. Lipophilic compound-mediated gene expression and implication for intervention in reactive oxygen species (ROS)-related diseases: mini-review. Nutrients 2010;2(7):725-36.

[80] Ohta A, Uitto J. Procollagen gene expression by scleroderma fibroblasts in culture. Inhibition of collagen production and reduction of pro alpha 1(I) and pro alpha 1(III) collagen messenger RNA steady-state levels by retinoids. Arthritis Rheum 1987;30(4):404-11.

[81] Cracowski JL, Girolet S, Imbert B, Seinturier C, Stanke-Labesque F, Bessard J, Boignard A, Bessard G, Carpentier PH. Effects of short-term treatment with vitamin $\mathrm{E}$ in systemic sclerosis: a double blind, randomized, controlled clinical trial of efficacy based on urinary isoprostane measurement. Free Radic Biol Med 2005;38(1):98-103.

[82] Herrick AL, Hollis S, Schofield D, Rieley F, Blann A, Griffin K, Moore T, Braganza JM, Jayson MI. A double-blind placebo-controlled trial of antioxidant therapy in limited cutaneous systemic sclerosis. Clin Exp Rheumatol 2000;18(3):349-56.

[83] de Souza RB, Macedo AR, Kuruma KA, Macedo PA, Borges CT. Pentoxyphylline in association with vitamin E reduces cutaneous fibrosis in systemic sclerosis. Clin Rheumatol 2009;28(10):1207-12. 
[84] Ostojic P, Damjanov N. Effects of micronutrient antioxidants (alpha-tocopherol and ascorbic acid) on skin thickening and lung function in patients with early diffuse systemic sclerosis. Rheumatol Int 2011;31(8):1051-4.

[85] Fiori G, Galluccio F, Braschi F, Amanzi L, Miniati I, Conforti ML, Del Rosso A, Generini S, Candelieri A, Magonio A and others. Vitamin E gel reduces time of healing of digital ulcers in systemic sclerosis. Clin Exp Rheumatol 2009;27(3 Suppl 54):51-4.

[86] Kremer JM. Treatment of systemic sclerosis with topical tretinoin: report of two cases. Arthritis Rheum 1996;39(6):1070.

[87] Ikeda T, Uede K, Hashizume H, Furukawa F. The Vitamin A derivative etretinate improves skin sclerosis in patients with systemic sclerosis. J Dermatol Sci 2004;34(1):62-6.

[88] Samuni Y, Goldstein S, Dean OM, Berk M. The chemistry and biological activities of $\mathrm{N}$-acetylcysteine. Biochim Biophys Acta 2013;1830(8):4117-29.

[89] Meister A, Anderson ME. Glutathione. Annu Rev Biochem 1983;52:711-60.

[90] Rushworth GF, Megson IL. Existing and potential therapeutic uses for Nacetylcysteine: the need for conversion to intracellular glutathione for antioxidant benefits. Pharmacol Ther 2014;141(2):150-9.

[91] Deponte M. Glutathione catalysis and the reaction mechanisms of glutathionedependent enzymes. Biochim Biophys Acta 2013;1830(5):3217-66.

[92] Aldini G, Altomare A, Baron G, Vistoli G, Carini M, Borsani L, Sergio F. NAcetylcysteine as an antioxidant and disulphide breaking agent: the reasons why. Free Radic Res 2018;52(7):751-762.

[93] Furst DE, Clements PJ, Harris R, Ross M, Levy J, Paulus HE. Measurement of clinical change in progressive systemic sclerosis: a 1 year doubleblind placebo-controlled trial of N-acetylcysteine. Ann Rheum Dis 1979;38(4):356-61.

[94] Correa MJ, Mariz HA, Andrade LE, Kayser C. [Oral N-acetylcysteine in the treatment of Raynaud's phenomenon secondary to systemic sclerosis: a randomized, double-blind, placebo-controlled clinical trial]. Rev Bras Reumatol 2014;54(6):452-8.

[95] Rosato E, Borghese F, Pisarri S, Salsano F. The treatment with N-acetylcysteine of Raynaud's phenomenon and ischemic ulcers therapy in sclerodermic patients: a prospective observational study of 50 patients. Clin Rheumatol 2009;28(12):1379-84.

[96] Rosato E, Rossi C, Molinaro I, Giovannetti A, Pisarri S, Salsano F. Long-term $\mathrm{N}$-acetylcysteine therapy in systemic sclerosis interstitial lung disease: a retrospective study. Int J Immunopathol Pharmacol 2011;24(3):727-33.

[97] Rosato E, Cianci R, Barbano B, Menghi G, Gigante A, Rossi C, Zardi EM, Amoroso A, Pisarri S, Salsano F. N-acetylcysteine infusion reduces the resistance index of renal artery in the early stage of systemic sclerosis. Acta Pharmacol Sin 2009;30(9):1283-8.

[98] Herbert CM, Lindberg KA, Jayson MI, Bailey AJ. Biosynthesis and maturation of skin collagen in scleroderma, and effect of D-penicillamine. Lancet 1974;1(7850):187-92. 
[99] Nimni ME. A defect in the intramolecular and intermolecular cross-linking of collagen caused by penicillamine. I. Metabolic and functional abnormalities in soft tissues. J Biol Chem 1968;243(7):1457-66.

[100] Nimni ME. Penicillamine and collagen metabolism. Scand J Rheumatol Suppl 1979(28):71-8.

[101] Uitto J, Helin P, Rasmussen O, Lorenzen I. Skin collagen in patients with scleroderma: biosynthesis and maturation in vitro, and the effect of Dpenicillamine. Ann Clin Res 1970;2(3):228-34.

[102] Trachootham D, Lu W, Ogasawara MA, Nilsa RD, Huang P. Redox regulation of cell survival. Antioxid Redox Signal 2008;10(8):1343-74.

[103] Wadhwa S, Mumper RJ. D-penicillamine and other low molecular weight thiols: review of anticancer effects and related mechanisms. Cancer Lett 2013;337(1):8-21.

[104] Harris ED, Jr., Sjoerdsma A. Effect of penicillamine on human collagen and its possible application to treatment of scleroderma. Lancet 1966;2(7471):996-9.

[105] Fulghum DD, Katz R. Penicillamine for scleroderma. Arch Dermatol 1968;98(1):51-2.

[106] Bluestone R, Grahame R, Holloway V, Holt PJ. Treatment of systemic sclerosis with D-penicillamine. A new method of obserying the effects of treatment. Ann Rheum Dis 1970;29(2):153-8.

[107] Jayson MI, Lovell C, Black CM, Wilson RS.Penicillamine therapy in systemic sclerosis. Proc R Soc Med 1977;70 Suppl 3:82-8.

[108] Furst DE, Clements PJ. D-penicillamine is not an effective treatment in systemic sclerosis. Scand J Rheumatol 2001;30(4):189-91.

[109] Medsger TA, Jr., Lucas M, Wildy KS, Baker C. D-penicillamine in systemic sclerosis? Yes! Scand J Rheumatol 2001;30(4):192-4.

[110] Clements PJ, Seibold JR, Furst DE, Mayes M, White B, Wigley F, Weisman MD, Barr W, Moreland L, Medsger TA, Jr. and others. High-dose versus lowdose D-penicillamine in early diffuse systemic sclerosis trial: lessons learned. Semin Arthritis Rheum 2004;33(4):249-63.

[111] Derk CT, Huaman G, Jimenez SA. A retrospective randomly selected cohort study of D-penicillamine treatment in rapidly progressive diffuse cutaneous systemic sclerosis of recent onset. Br J Dermatol 2008;158(5):1063-8.

[112] Steen VD, Medsger TA, Jr. Improvement in skin thickening in systemic sclerosis associated with improved survival. Arthritis Rheum 2001;44(12):2828-35.

[113] Jimenez SA, Sigal SH. A 15-year prospective study of treatment of rapidly progressive systemic sclerosis with D-penicillamine [see comment]. J Rheumatol 1991;18(10):1496-503.

[114] Derk CT, Jimenez SA. Goodpasture-like syndrome induced by D-penicillamine in a patient with systemic sclerosis: report and review of the literature. $\mathrm{J}$ Rheumatol 2003;30(7):1616-20.

[115] Dawkins RL, Zilko PJ, Carrano J, Garlepp MJ, McDonald BL. Immunobiology of D-penicillamine. J Rheumatol Suppl 1981;7:56-61.

[116] Stocker R. Molecular mechanisms underlying the antiatherosclerotic and antidiabetic effects of probucol, succinobucol, and other probucol analogues. Curr Opin Lipidol 2009;20(3):227-35. 
[117] Witting PK, Wu BJ, Raftery M, Southwell-Keely P, Stocker R. Probucol protects against hypochlorite-induced endothelial dysfunction: identification of a novel pathway of probucol oxidation to a biologically active intermediate. J Biol Chem 2005;280(16):15612-8.

[118] Deng YM, Wu BJ, Witting PK, Stocker R. Probucol protects against smooth muscle cell proliferation by upregulating heme oxygenase-1. Circulation 2004;110(13):1855-60.

[119] Alam J, Stewart D, Touchard C, Boinapally S, Choi AM, Cook JL. Nrf2, a Cap'n'Collar transcription factor, regulates induction of the heme oxygenase-1 gene. J Biol Chem 1999;274(37):26071-8.

[120] Takabe W, Matsukawa N, Kodama T, Tanaka K, Noguchi N. Chemical structure-dependent gene expression of proteasome subunits via regulation of the antioxidant response element. Free Radic Res 2006;40(1):21-30.

[121] Zucoloto AZ, Manchope MF, Staurengo-Ferrari L, Pinho-Ribeiro FA, Zarpelon AC, Saraiva ALL, Cecilio NT, Alves-Filho JC, Cunha TM, Menezes GB and others. Probucol attenuates lipopolysaccharide-induced leukocyte recruitment and inflammatory hyperalgesia: effect on NF-small ka, CyrillicB activation and cytokine production. Eur J Pharmacol 2017;809:52-63.

[122] Jiang JL, Zhang XH, Li NS, Rang WQ, Feng X, Hu CP, Li YJ, Deng HW. Probucol decreases asymmetrical dimethylarginine level by alternation of protein arginine methyltransferase I and dimethylarginine dimethylaminohydrolase activity. Cardiovasc Drugs Ther 2006;20(4):281-94.

[123] Singla DK, Kaur K, Sharma AK, Dhingra S, Singal PK. Probucol promotes endogenous antioxidant reserve and confers protection against reperfusion injury. Can J Physiol Pharmacol 2007;85(3-4):439-43.

[124] Denton CP, Bunce TD, Dorado MB, Roberts Z, Wilson H, Howell K, Bruckdorfer KR, Black CM. Probucol improves symptoms and reduces lipoprotein oxidation susceptibility in patients with Raynaud's phenomenon. Rheumatology (Oxford) 1999;38(4):309-15.

[125] Wassmann S, Laufs U, Muller K, Konkol C, Ahlbory K, Baumer AT, Linz W, Bohm M, Nickenig G. Cellular antioxidant effects of atorvastatin in vitro and in vivo. Arterioscler Thromb Vasc Biol 2002;22(2):300-5.

[126] Laufs U, Liao JK. Post-transcriptional regulation of endothelial nitric oxide synthase mRNA stability by Rho GTPase. J Biol Chem 1998;273(37):24266-71.

[127] Ming XF, Viswambharan H, Barandier C, Ruffieux J, Kaibuchi K, Rusconi S, Yang Z. Rho GTPase/Rho kinase negatively regulates endothelial nitric oxide synthase phosphorylation through the inhibition of protein kinase B/Akt in human endothelial cells. Mol Cell Biol 2002;22(24):8467-77.

[128] Feron O, Dessy C, Desager JP, Balligand JL. Hydroxy-methylglutarylcoenzyme A reductase inhibition promotes endothelial nitric oxide synthase activation through a decrease in caveolin abundance. Circulation 2001;103(1):113-8.

[129] Kleikers PW, Wingler K, Hermans JJ, Diebold I, Altenhofer S, Radermacher KA, Janssen B, Gorlach A, Schmidt HH. NADPH oxidases as a source of oxidative stress and molecular target in ischemia/reperfusion injury. J Mol Med (Berl) 2012;90(12):1391-406. 
[130] Brandes RP, Beer S, Ha T, Busse R. Withdrawal of cerivastatin induces monocyte chemoattractant protein 1 and tissue factor expression in cultured vascular smooth muscle cells. Arterioscler Thromb Vasc Biol 2003;23(10):1794-800.

[131] Christ M, Bauersachs J, Liebetrau C, Heck M, Gunther A, Wehling M. Glucose increases endothelial-dependent superoxide formation in coronary arteries by $\mathrm{NAD}(\mathrm{P}) \mathrm{H}$ oxidase activation: attenuation by the 3-hydroxy-3-methylglutaryl coenzyme A reductase inhibitor atorvastatin. Diabetes 2002;51(8):2648-52.

[132] Wei YM, Li X, Xiong J, Abais JM, Xia M, Boini KM, Zhang Y, Li PL. Attenuation by statins of membrane raft-redox signaling in coronary arterial endothelium. J Pharmacol Exp Ther 2013;345(2):170-9.

[133] Wagner AH, Kohler T, Ruckschloss U, Just I, Hecker M. Improvement of nitric oxide-dependent vasodilatation by HMG-CoA reductase inhibitors through attenuation of endothelial superoxide anion formation. Arterioscler Thromb Vasc Biol 2000;20(1):61-9.

[134] Antoniades C, Bakogiannis C, Tousoulis D, Reilly S, Zhang MH, Paschalis A, Antonopoulos AS, Demosthenous M, Miliou A, Psarros C and others. Preoperative atorvastatin treatment in $\mathrm{CABG}$ patients rapidly improves vein graft redox state by inhibition of Rac1 and NADPH-oxidase activity. Circulation 2010;122(11 Suppl):S66-73.

[135] Kurusu A, Shou I, Nakamura S, Fukui M, Shirato I, Tomino Y. Effects of the new hydroxy-3-methylglutaryl coenzyme a reductase inhibitor fluvastatin on anti-oxidant enzyme activities and renal function in streptozotocin-induced diabetic rats. Clin Exp Pharmacol Physiol 2000;27(10):767-70.

[136] Zhu B, Shen H, Zhou J, Lin F, Hu Y. Effects of simvastatin on oxidative stress in streptozotocin-induced diabetic rats: a role for glomeruli protection. Nephron Exp Nephrol 2005;101(1):e1-8.

[137] Perez-Guerrero C, Alvarez de Sotomayor M, Jimenez L, Herrera MD, Marhuenda E. Effects of simvastatin on endothelial function after chronic inhibition of nitric oxide synthase by L-NAME. J Cardiovasc Pharmacol 2003;42(2):204-10.

[138] Colucci R, Fornai M, Duranti E, Antonioli L, Rugani I, Aydinoglu F, Ippolito C, Segnani C, Bernardini N, Taddei S and others. Rosuvastatin prevents angiotensin II-induced vascular changes by inhibition of NAD(P)H oxidase and COX-1. Br J Pharmacol 2013;169(3):554-66.

[139] Dichtl W, Dulak J, Frick M, Alber HF, Schwarzacher SP, Ares MP, Nilsson $\mathrm{J}$, Pachinger O, Weidinger F. HMG-CoA reductase inhibitors regulate inflammatory transcription factors in human endothelial and vascular smooth muscle cells. Arterioscler Thromb Vasc Biol 2003;23(1):58-63.

[140] Ladak K, Pope JE. A review of the effects of statins in systemic sclerosis. Semin Arthritis Rheum 2016;45(6):698-705.

[141] Del Papa N, Cortiana M, Vitali C, Silvestris I, Maglione W, Comina DP, Lucchi T, Cortelezzi A. Simvastatin reduces endothelial activation and damage but is partially ineffective in inducing endothelial repair in systemic sclerosis. J Rheumatol 2008;35(7):1323-8.

[142] Abou-Raya A, Abou-Raya S, Helmii M. Statins: potentially useful in therapy of systemic sclerosis-related Raynaud's phenomenon and digital ulcers. J Rheumatol 2008;35(9):1801-8. 
[143] Timar O, Szekanecz Z, Kerekes G, Vegh J, Olah AV, Nagy G, Csiki Z, Danko K, Szamosi S, Nemeth A and others. Rosuvastatin improves impaired endothelial function, lowers high sensitivity CRP, complement and immuncomplex production in patients with systemic sclerosis--a prospective case-series study. Arthritis Res Ther 2013;15(5):R105.

[144] Kuwana M, Okazaki Y, Kaburaki J. Long-term beneficial effects of statins on vascular manifestations in patients with systemic sclerosis. Mod Rheumatol 2009;19(5):530-5.

[145] Rossi M, Bazzichi L, Ghiadoni L, Mencaroni I, Franzoni F, Bombardieri S. Increased finger skin vasoreactivity and stimulated vasomotion associated with simvastatin therapy in systemic sclerosis hypercholesterolemic patients. Rheumatol Int 2012;32(12):3715-21.

[146] Furukawa S, Yasuda S, Amengual O, Horita T, Atsumi T, Koike T. Protective effect of pravastatin on vascular endothelium in patients with systemic sclerosis: a pilot study. Ann Rheum Dis 2006;65(8):1118-20.

[147] Sadik HY, Moore TL, Vail A, Murray A, Anderson M, Blann A, Herrick AL. Lack of effect of 8 weeks atorvastatin on microvascular endothelial function in patients with systemic sclerosis. Rheumatology (Oxford) 2010;49(5):990-6.

[148] Tsou PS, Talia NN, Pinney AJ, Kendzicky A, Piera-Velazquez S, Jimenez SA, Seibold JR, Phillips K, Koch AE. Effect of oxidative stress on protein tyrosine phosphatase 1B in scleroderma dermal fibroblasts. Arthritis Rheum 2012;64(6):1978-89.

[149] Rothstein JD. Edaravone: A new drug approyed for ALS. Cell 2017;171(4):725.

[150] Wang HM, Zhang T, Huang JK, Xiang JY, Chen JJ, Fu JL, Zhao YW. Edaravone Attenuates the Proinflammatory Response in Amyloid-beta-Treated Microglia by Inhibiting NLRP3 Inflammasome-Mediated IL-1 beta Secretion. Cell Physiol Biochem 2017;43(3):1113-1125.

[151] Mikawa K, Akamatsu H, Nishina K, Obara H, Niwa Y. Effects of edaravone on human neutrophil function. Acta Anaesthesiol Scand 2005;49(3):385-9.

[152] Watanabe T, Tahara M, Todo S. The novel antioxidant edaravone: from bench to bedside. Cardiovasc Ther 2008;26(2):101-14.

[153] Yoshizaki A, Yanaba K, Ogawa A, Iwata Y, Ogawa F, Takenaka M, Shimizu K, Asano Y, Kadono T, Sato S. The specific free radical scavenger edaravone suppresses fibrosis in the bleomycin-induced and tight skin mouse models of systemic sclerosis. Arthritis Rheum 2011;63(10):3086-97.

[154] Park S, Karunakaran U, Jeoung NH, Jeon JH, Lee IK. Physiological effect and therapeutic application of alpha lipoic acid. Curr Med Chem 2014;21(32):3636-45.

[155] Jones W, Li X, Qu ZC, Perriott L, Whitesell RR, May JM. Uptake, recycling, and antioxidant actions of alpha-lipoic acid in endothelial cells. Free Radic Biol Med 2002;33(1):83-93.

[156] Wada H, Shintani D, Ohlrogge J. Why do mitochondria synthesize fatty acids? Evidence for involvement in lipoic acid production. Proc Natl Acad Sci U S A 1997;94(4):1591-6.

[157] Biewenga GP, Haenen GR, Bast A. The pharmacology of the antioxidant lipoic acid. Gen Pharmacol 1997;29(3):315-31. 
[158] Bast A, Haenen GR. Lipoic acid: a multifunctional antioxidant. Biofactors 2003;17(1-4):207-13.

[159] Petersen Shay K, Moreau RF, Smith EJ, Hagen TM. Is alpha-lipoic acid a scavenger of reactive oxygen species in vivo? Evidence for its initiation of stress signaling pathways that promote endogenous antioxidant capacity. IUBMB Life 2008;60(6):362-7.

[160] Busse E, Zimmer G, Schopohl B, Kornhuber B. Influence of alpha-lipoic acid on intracellular glutathione in vitro and in vivo. Arzneimittelforschung 1992;42(6):829-31.

[161] Han D, Handelman G, Marcocci L, Sen CK, Roy S, Kobuchi H, Tritschler HJ, Flohe L, Packer L. Lipoic acid increases de novo synthesis of cellular glutathione by improving cystine utilization. Biofactors 1997;6(3):321-38.

[162] Mary J, Vougier S, Picot CR, Perichon M, Petropoulos I, Friguet B. Enzymatic reactions involved in the repair of oxidized proteins. Exp Gerontol 2004;39(8):1117-23.

[163] Ying Z, Kampfrath T, Sun Q, Parthasarathy S, Rajagopalan S. Evidence that alpha-lipoic acid inhibits NF-kappaB activation independent of its antioxidant function. Inflamm Res 2011;60(3):219-25.

[164] Ou P, Tritschler HJ, Wolff SP. Thioctic (lipoic) acid: a therapeutic metalchelating antioxidant? Biochem Pharmaco1 1995;50(1):123-6.

[165] Goralska M, Dackor R, Holley B, McGahan MC. Alpha lipoic acid changes iron uptake and storage in lens epithelial cells. Exp Eye Res 2003;76(2):241-8.

[166] Tsou PS, Balogh B, Pinney AJ, Zakhem G, Lozier A, Amin MA, Stinson WA, Schiopu E, Khanna D, Fox DA and others. Lipoic acid plays a role in scleroderma: insights obtained from scleroderma dermal fibroblasts. Arthritis Res Ther 2014;16(5):411.

[167] Kavian N, Marut W, Servettaz A, Nicco C, Chereau C, Lemarechal H, Guilpain P, Chimini G, Galland F, Weill B and others. Pantethine Prevents Murine Systemic Sclerosis Through the Inhibition of Microparticle Shedding. Arthritis Rheumatol 2015;67(7):1881-90.

[168] Bian D, Zhang J, Wu X, Dou Y, Yang Y, Tan Q, Xia Y, Gong Z, Dai Y. Asiatic acid isolated from Centella asiatica inhibits TGF-beta1-induced collagen expression in human keloid fibroblasts via PPAR-gamma activation. Int J Biol Sci 2013;9(10):1032-42.

[169] Xia X, Dai C, Yu H, Huang X, Chen A, Tan Y, Wang L. Asiatic acid prevents the development of interstitial lung disease in a hypochlorous acid-induced mouse model of scleroderma. Oncol Lett 2018;15(6):8711-8716.

[170] Liu M, Yang J, Li M. Tanshinone IIA attenuates interleukin-17A-induced systemic sclerosis patient-derived dermal vascular smooth muscle cell activation via inhibition of the extracellular signal-regulated kinase signaling pathway. Clinics (Sao Paulo) 2015;70(4):250-6.

[171] Song Y, Zhu L, Li M. Antifibrotic effects of crocetin in scleroderma fibroblasts and in bleomycin-induced sclerotic mice. Clinics (Sao Paulo) 2013;68(10):1350-7.

[172] Dooley A, Shi-Wen X, Aden N, Tranah T, Desai N, Denton CP, Abraham DJ, Bruckdorfer R. Modulation of collagen type I, fibronectin and dermal 
fibroblast function and activity, in systemic sclerosis by the antioxidant epigallocatechin-3-gallate. Rheumatology (Oxford) 2010;49(11):2024-36.

[173] Dooley A, Bruckdorfer KR, Abraham DJ. Modulation of fibrosis in systemic sclerosis by nitric oxide and antioxidants. Cardiol Res Pract 2012;2012:521958.

[174] Venkatesan N, Punithavathi V, Chandrakasan G. Curcumin protects bleomycininduced lung injury in rats. Life Sci 1997;61(6):PL51-8.

[175] Tourkina E, Gooz P, Oates JC, Ludwicka-Bradley A, Silver RM, Hoffman S. Curcumin-induced apoptosis in scleroderma lung fibroblasts: role of protein kinase cepsilon. Am J Respir Cell Mol Biol 2004;31(1):28-35.

[176] Rushworth SA, Ogborne RM, Charalambos CA, O'Connell MA. Role of protein kinase $\mathrm{C}$ delta in curcumin-induced antioxidant response element-mediated gene expression in human monocytes. Biochem Biophys Res Commun 2006;341(4):1007-16.

[177] Song K, Peng S, Sun Z, Li H, Yang R. Curcumin suppresses TGF-beta signaling by inhibition of TGIF degradation in scleroderma fibroblasts. Biochem Biophys Res Commun 2011;411(4):821-5.

[178] Aggarwal BB, Sundaram C, Malani N, Ichikawa H. Curcumin: the Indian solid gold. Adv Exp Med Biol 2007;595:1-75.

[179] Sharma RA, Steward WP, Gescher AJ. Pharmacokinetics and pharmacodynamics of curcumin. Adv Exp Med Biøl 2007;595:453-70.

[180] Smulik R, Debski D, Zielonka J, Michalowski B, Adamus J, Marcinek A, Kalyanaraman B, Sikora A. Nitroxyl (HNO) reacts with molecular oxygen and forms peroxynitrite at physiological $\mathrm{pH}$. Biological Implications. J Biol Chem 2014;289(51):35570-81.

[181] Samarakoon R, Overstreet JM, Higgins PJ. TGF-beta signaling in tissue fibrosis: redox controls, target genes and therapeutic opportunities. Cell Signal 2013;25(1):264-8

[182] Cucoranu I, Clempus R, Dikalova A, Phelan PJ, Ariyan S, Dikalov S, Sorescu D. NAD(P)H oxidase 4 mediates transforming growth factor-beta1induced differentiation of cardiac fibroblasts into myofibroblasts. Circ Res 2005;97(9):900-7.

[183] Sturrock A, Cahill B, Norman K, Huecksteadt TP, Hill K, Sanders K, Karwande SV, Stringham JC, Bull DA, Gleich M and others. Transforming growth factor-beta1 induces Nox4 NAD(P)H oxidase and reactive oxygen speciesdependent proliferation in human pulmonary artery smooth muscle cells. Am J Physiol Lung Cell Mol Physiol 2006;290(4):L661-L673.

[184] Jiang F, Zhang Y, Dusting GJ. NADPH oxidase-mediated redox signaling: roles in cellular stress response, stress tolerance, and tissue repair. Pharmacol Rev 2011;63(1):218-42.

[185] Barcellos-Hoff MH, Dix TA. Redox-mediated activation of latent transforming growth factor-beta 1. Mol Endocrinol 1996;10(9):1077-83.

[186] Leonarduzzi G, Scavazza A, Biasi F, Chiarpotto E, Camandola S, Vogel S, Dargel R, Poli G. The lipid peroxidation end product 4-hydroxy-2,3nonenal up-regulates transforming growth factor betal expression in the macrophage lineage: a link between oxidative injury and fibrosclerosis. FASEB J 1997;11(11):851-7. 
[187] Hecker L, Vittal R, Jones T, Jagirdar R, Luckhardt TR, Horowitz JC, Pennathur S, Martinez FJ, Thannickal VJ. NADPH oxidase-4 mediates myofibroblast activation and fibrogenic responses to lung injury. Nat Med 2009;15(9):1077-81.

[188] Teixeira G, Szyndralewiez C, Molango S, Carnesecchi S, Heitz F, Wiesel P, Wood JM. Therapeutic potential of NADPH oxidase 1/4 inhibitors. Br J Pharmacol 2017;174(12):1647-1669.

[189] Murphy-Marshman H, Quensel K, Shi-Wen X, Barnfield R, Kelly J, Peidl A, Stratton RJ, Leask A. Antioxidants and NOX1/NOX4 inhibition blocks TGFbeta1-induced CCN2 and alpha-SMA expression in dermal and gingival fibroblasts. PLoS One 2017;12(10):e0186740.

[190] Parnham MJ, Erakovic Haber V, Giamarellos-Bourboulis EJ, Perletti G, Verleden GM, Vos R. Azithromycin: mechanisms of action and their relevance for clinical applications. Pharmacol Ther 2014;143(2):225-45.

[191] Tsubouchi K, Araya J, Minagawa S, Hara H, Ichikawa A, Saito N, Kadota T, Sato N, Yoshida M, Kurita Y and others. Azithromycin attenuates myofibroblast differentiation and lung fibrosis development through proteasomal degradation of NOX4. Autophagy 2017;13(8):1420-1434.

[192] Dosoki H, Stegemann A, Taha M, Schnittler H, Luger TA, Schroder K, Distler $\mathrm{JH}$, Kerkhoff C, Bohm M. Targeting of NADPH oxidase in vitro and in vivo suppresses fibroblast activation and experimental skin fibrosis. Exp Dermatol 2017;26(1):73-81.

[193] Pignatelli P, Carnevale R, Pastori D, Cangemi R, Napoleone L, Bartimoccia S, Nocella C, Basili S, Violi F. Immediate antioxidant and antiplatelet effect of atorvastatin via inhibition of Nox2. Circulation 2012;126(1):92-103.

[194] Pignatelli P, Carnevale R, Di Santo S, Bartimoccia S, Nocella C, Vicario T, Loffredo L, Angelico F, Violi F. Rosuvastatin reduces platelet recruitment by inhibiting NADPH oxidase activation. Biochem Pharmacol 2012;84(12):1635-42.

[195] Zhou G, Wang Y, He P, Li D. Probucol inhibited Nox2 expression and attenuated podocyte injury in type 2 diabetic nephropathy of $\mathrm{db} / \mathrm{db}$ mice. Biol Pharm Bull 2013;36(12):1883-90.

[196] ZhuBB, Wang H, Chi YF, Wang YM, Yao XM, Liu S, Qiu H, Fang J, Yin PH, Zhang XM and others. Protective effects of probucol on OxLDL-induced epithelial-mesenchymal transition in human renal proximal tubular epithelial cells via LOX1/ROS/MAPK signaling. Mol Med Rep 2018;17(1):1289-1296.

[197] Cruz-Solbes AS, Youker K. Epithelial to Mesenchymal Transition (EMT) and Endothelial to Mesenchymal Transition (EndMT): Role and Implications in Kidney Fibrosis. Results Probl Cell Differ 2017;60:345-372.

[198] O'Neill HC, Rancourt RC, White CW. Lipoic acid suppression of neutrophil respiratory burst: effect of NADPH. Antioxid Redox Signal 2008;10(2):277-85.

[199] Dong Y, Wang H, Chen Z. Alpha-Lipoic Acid Attenuates Cerebral Ischemia and Reperfusion Injury via Insulin Receptor and PI3K/Akt-Dependent Inhibition of NADPH Oxidase. Int J Endocrinol 2015;2015:903186. 
Table. 1. Interventional study with antioxidant

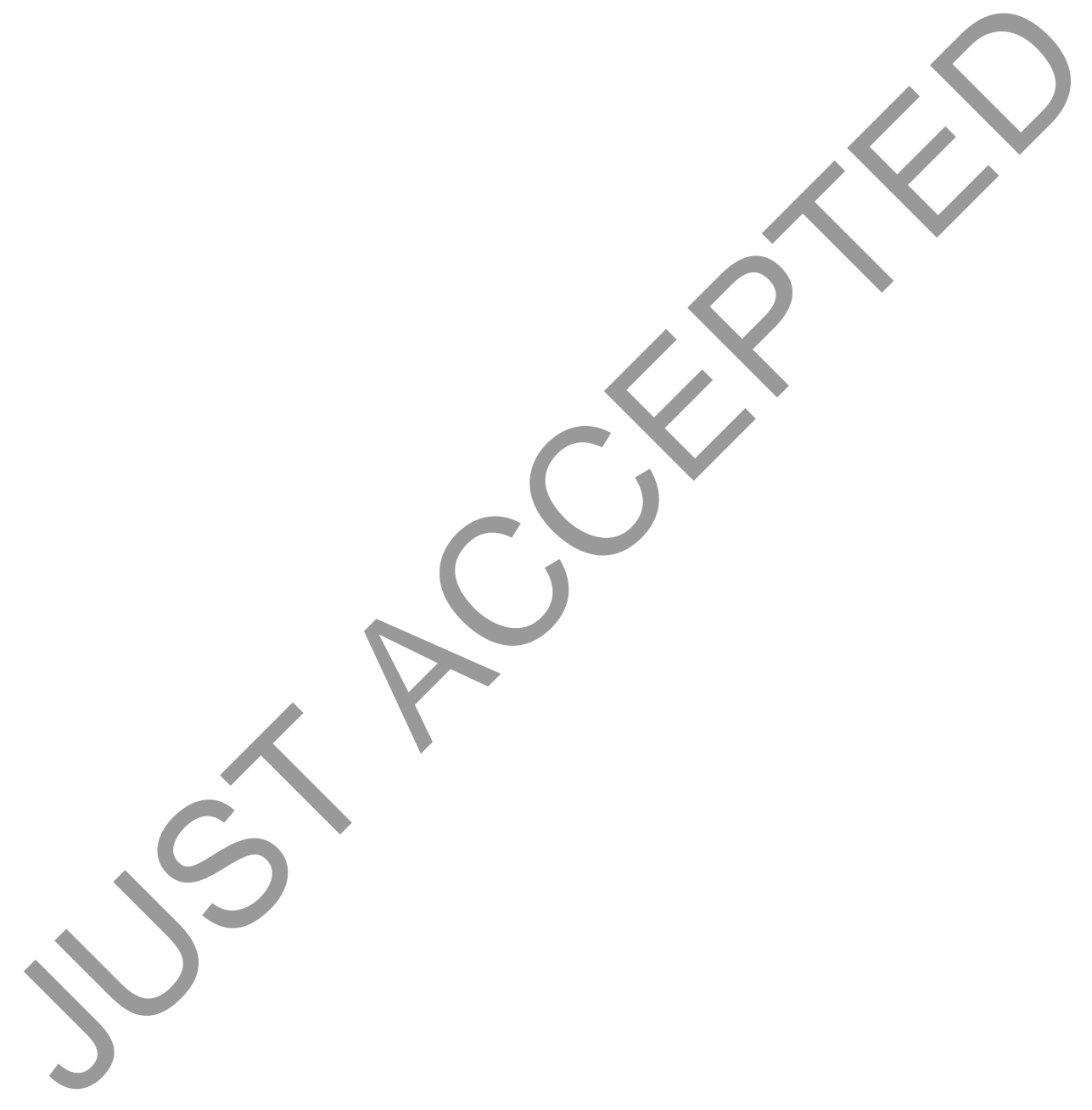




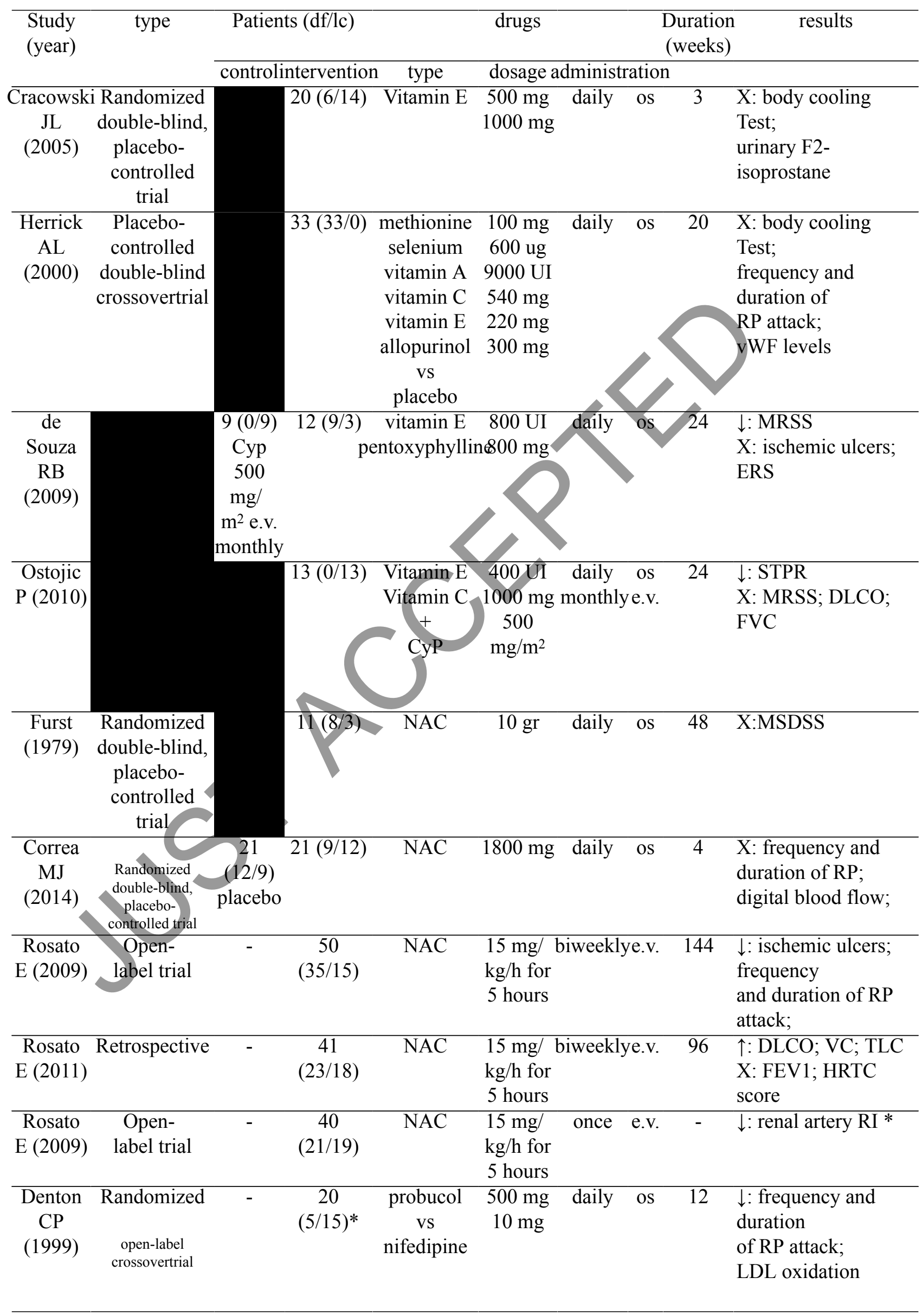




\begin{tabular}{|c|c|c|c|c|c|c|c|c|}
\hline $\begin{array}{l}\text { Sadik } \\
\text { HY } \\
(2010)\end{array}$ & $\begin{array}{l}\text { Randomized } \\
\text { double-blind, } \\
\text { placebo- } \\
\text { controlled trial }\end{array}$ & $\begin{array}{c}18 \\
(3 / 15) \\
\text { placebo }\end{array}$ & $\begin{array}{c}36 \\
(19 / 17)\end{array}$ & atorvastatin & $20 \mathrm{mg}$ daily & os & 8 & $\begin{array}{l}\text { X: frequency and } \\
\text { duration } \\
\text { of RP attack; } \\
\text { digital blood flow; } \\
\text { NVC alteration; } \\
\text { vWf; hsPCR }\end{array}$ \\
\hline $\begin{array}{c}\text { Jimenez } \\
\text { SA } \\
(1991)\end{array}$ & $\begin{array}{c}\text { Prospective } \\
\text { observational }\end{array}$ & - & $69(69 / 0)$ & PEN & $750 \mathrm{mg}$ daily & os & 180 & $\downarrow:$ MRSS \\
\hline $\begin{array}{c}\text { Clements } \\
\text { PJ } \\
(1999)\end{array}$ & $\begin{array}{l}\text { Randomized } \\
\text { double- } \\
\text { blind- } \\
\text { controlled } \\
\text { trial }\end{array}$ & $\begin{array}{c}68 \\
(68 / 0) \\
\text { D-PEN } \\
125 \mathrm{mg} \\
\text { alternate } \\
\text { days }^{\wedge}\end{array}$ & $66(66 / 0)$ & PEN & mg daily & os & 24 & $\begin{array}{l}\text { X:MRSS; renal } \\
\text { crisis; } \\
\text { overall mortality }\end{array}$ \\
\hline $\begin{array}{l}\text { Steen } \\
\text { VD } \\
(2001)\end{array}$ & $\begin{array}{c}\text { Prospective } \\
\text { observational }\end{array}$ & - & $\begin{array}{c}278 \\
(278 / 0)\end{array}$ & PEN & $750 \mathrm{mg}$ & & & $\begin{array}{l}\downarrow: \text { MRSS: overall } \\
\text { mortality }\end{array}$ \\
\hline $\begin{array}{c}\text { Derk CT } \\
(2008)\end{array}$ & Retrospective & - & $84(84 / 0)$ & PEN & $750_{1}$ & os & 96 & $\begin{array}{l}\downarrow \text { : cardiac, renal } \\
\text { and pulmonary } \\
\text { involvement } \\
\text { (MSDSS); } \\
\text { MRSS,TBS }\end{array}$ \\
\hline
\end{tabular}

Abbreviations: df: diffuse; lc: limited; X: No effect; $\downarrow$ : reduced; $\uparrow$ increased; vWF: von Willebrand factor; RP: Raynaud phenomena; MRSS: Modified Rodnan Skin Score; Cyp :cyclophosphamide; ESR; erythrocyte sedimentation rate; STPR: skin thickening progression rate; MSDSS: Medsger Scleroderma Disease Severity Scale; DLCO: diffusing coeffcient for carbon monoxide ;FVC: forced vital capacity; VC: vital capacity; TLC: total lung capacity; NAC:N-Acetylcysteine; HRTC: high resolution computed tomography; RI: resistance index; NVC: Nailfoldvideocapillaroscopy; hsPCR: high sensitive protein C reactive, TBS:total body surface. PEN: penicillamine. *This results was significant only for patients with early/active NVC pattern or MRSS $<14$. And not for patients with more advanced disease. ^ This dosage was considered ineffective and the authors used this group as a "placebo group" 


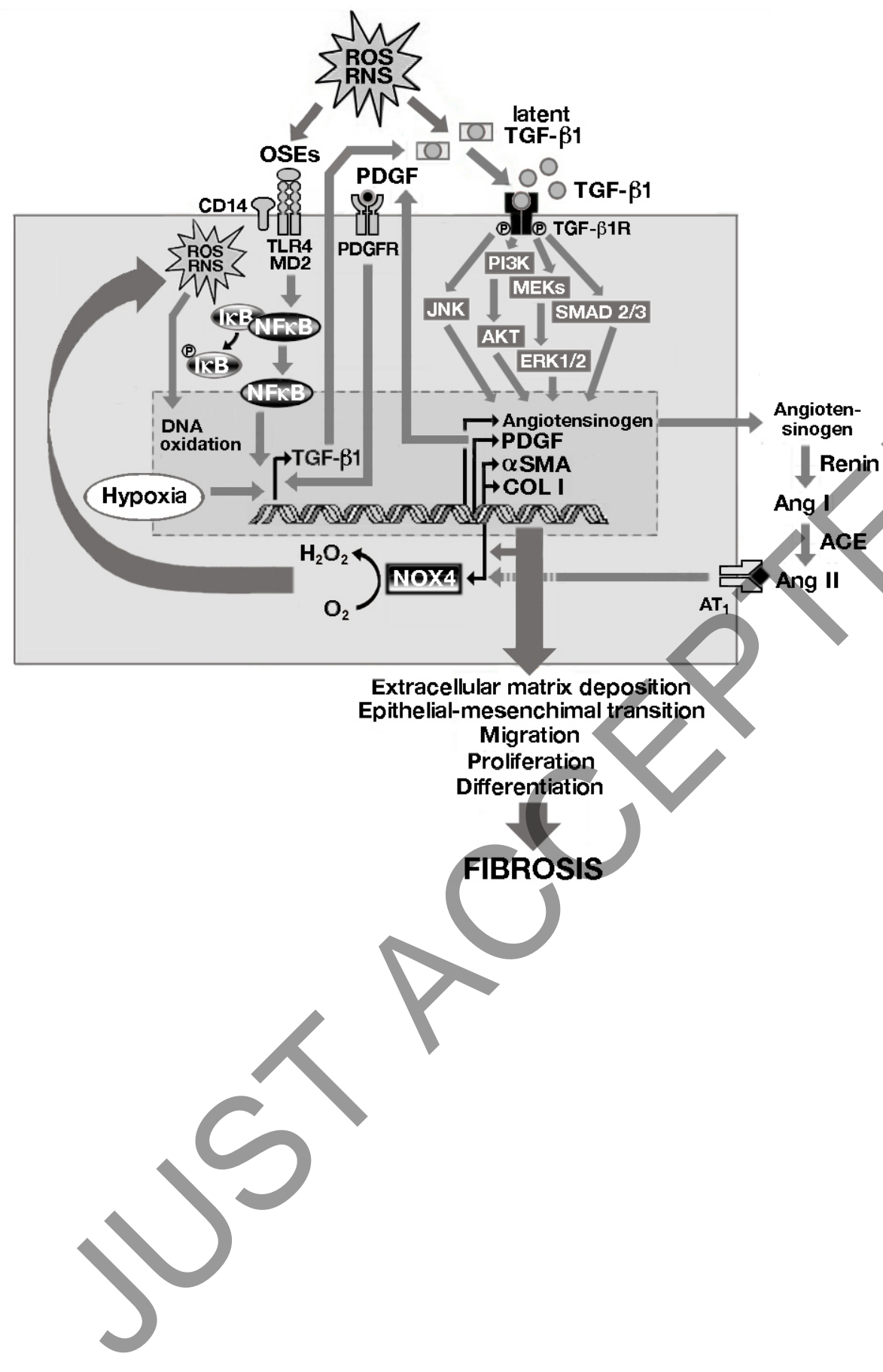




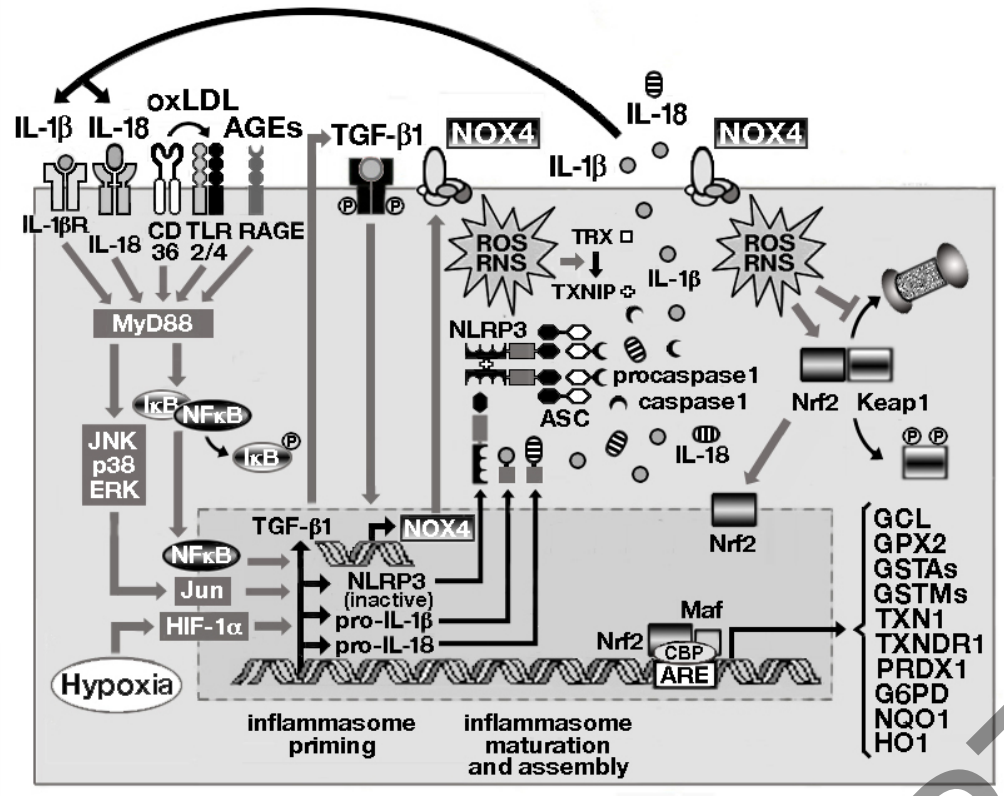




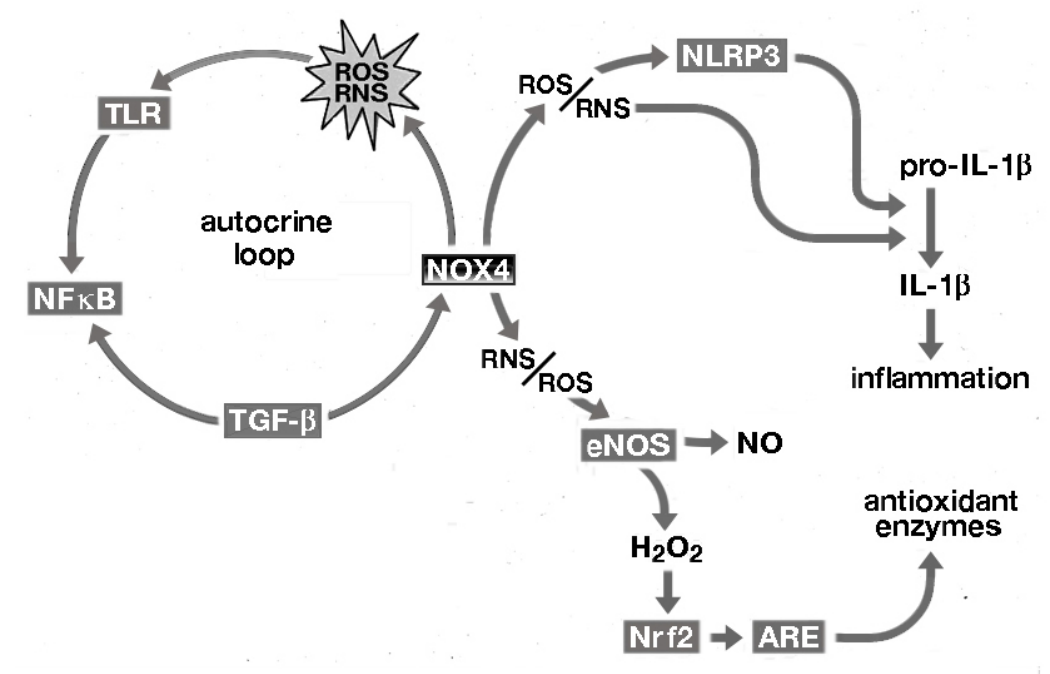

